\title{
Recent Advances in Asymmetric Catalytic Electrosynthesis
}

\author{
Cristiana Margarita $@$ and Helena Lundberg *(1) \\ Department of Chemistry, KTH Royal Institute of Technology, SE-100 44 Stockholm, Sweden; mcristia@kth.se \\ * Correspondence: hellundb@kth.se; Tel.: +46-8-790-8125
}

Received: 31 July 2020; Accepted: 26 August 2020; Published: 1 September 2020

check for updates

\begin{abstract}
The renewed interest in electrosynthesis demonstrated by organic chemists in the last years has allowed for rapid development of new methodologies. In this review, advances in enantioselective electrosynthesis that rely on catalytic amounts of organic or metal-based chiral mediators are highlighted with focus on the most recent developments up to July 2020. Examples of C-H functionalization, alkene functionalization, carboxylation and cross-electrophile couplings are discussed, along with their related mechanistic aspects.
\end{abstract}

Keywords: organic electrosynthesis; asymmetric catalysis; electrochemistry; enantioselectivity; organocatalysis; transition-metal catalysis

\section{Introduction}

The stereochemistry of organic compounds can dramatically influence their properties, such as biological activity of pharmaceuticals or macroscopic physical characteristics of polymers. Thus, the ability to control the stereochemical outcome in organic synthesis can be of great importance, and asymmetric catalysis is an indispensable tool in this endeavor. In asymmetric catalysis, racemic or prochiral substrates are converted to stereogenically enriched products with the aid of a chiral mediator in sub-stoichiometric amounts. As the catalyst is continually being reused in the process, the strategy presents great opportunities for highly atom-efficient processes. Traditionally, asymmetric catalysis has focused on two-electron transformations [1,2]. However, the toolbox of the organic chemist has been expanded tremendously in the last decade with the introduction of methods for asymmetric transformations with open-shell radical intermediate species using chemical, photochemical and electrochemical strategies [3-10].

In electrosynthesis, chemical redox reagents are replaced with electricity for the transformation of organic molecules. While dating back to the 19th century, the topic is currently receiving renewed interest due to its enabling potential for selective and sustainable synthesis [11-19]. In an electrochemical reaction, oxidation occurs at the anode and reduction at the cathode in a conductive medium. The redox processes can take place at constant current or constant potential in an undivided or divided electrochemical cell, where the latter separates the anodic and cathodic compartments by a conductive membrane [20]. The redox event that ultimately converts starting material to product in electrosynthesis can occur via different paths. As exemplified for a net-oxidative process, the electron transfer from a substrate to the anode can occur directly at the electrode surface (Figure 1a) or take place in solution with the aid of a homogeneous redox mediator. The latter represents indirect electrolysis (Figure 1b), where the mediator effectively acts as a catalyst for the electron transfer. The use of such redox mediators can facilitate the redox event from electrode to substrate and thereby reduce energy consumption and enable milder conditions with higher chemoselectivities [15,21]. In addition, electricity can be used to drive product formation by (re)generation of catalytically active species (Figure 1c). For clarity, we use the word "redox mediator" for electron transfer catalysts in this review, whereas "catalyst" 
denotes compounds added in catalytic amounts to mediate a transformation by other mechanistic action. In the context of asymmetric electrosynthesis, both redox mediators and catalysts can be chiral and induce stereoselectivity in the reaction in which they are used. Mechanistic insight can be crucial for rational development of new catalysts and synthetic protocols. To probe the reaction mechanism of electrosynthetic reactions, electroanalytical techniques such as cyclic voltammetry (CV) in combination with classic chemical approaches are commonly used [22].
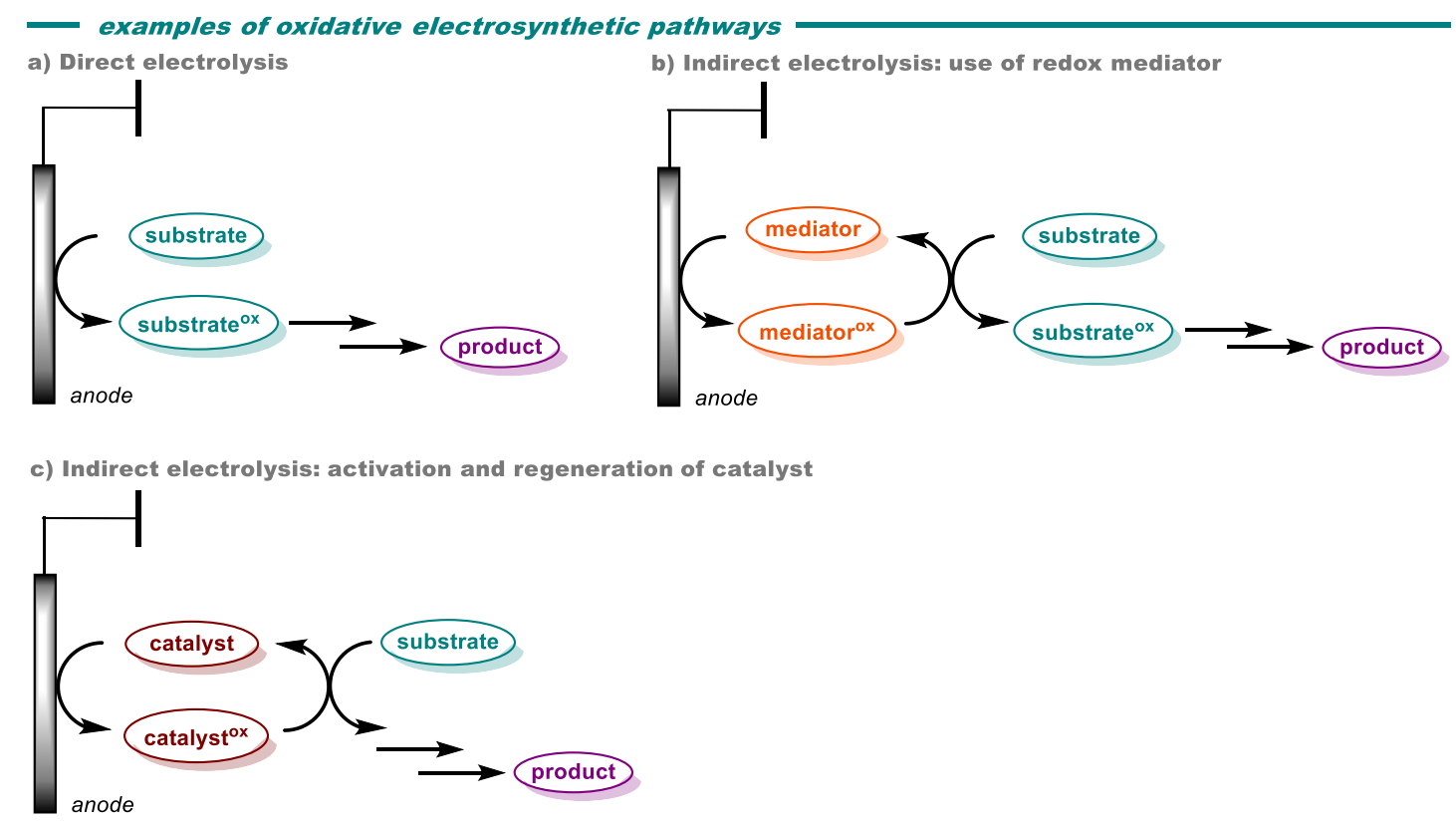

Figure 1. Examples of electrosynthetic pathways for substrate oxidation (cathodic reaction not shown) (a) direct anodic oxidation; (b) indirect anodic oxidation; (c) indirect oxidation by anodic activation and regeneration of catalyst.

In this review, electrosynthetic protocols that utilize catalytic amounts of small organic or metal-based chiral mediators to afford asymmetric induction in $\mathrm{C}-\mathrm{H}$ functionalization, alkene functionalization, carboxylation and cross-electrophile couplings are discussed, along with mechanistic aspects of the transformations. Other strategies for asymmetric electrosynthesis, e.g., biocatalysis, chiral auxiliaries, pre-functionalized chiral electrodes and chiral media have recently been covered elsewhere and will not be discussed here [3-6,23-25]. This review is divided into oxidative and reductive transformations and highlights recent developments up to July 2020.

\section{Oxidative Transformations}

\subsection{C-H Functionalization}

Asymmetric $\mathrm{C}-\mathrm{H}$ functionalization of $\alpha$-positions in carbonyl compounds through enamine intermediates is a well-explored topic in organocatalysis, often employing proline-derived catalysts [26]. In an electrochemical setting, Jang and co-workers reported on $\alpha$-oxyamination of aldehydes in the presence of the prolinol derivative (S)- $\alpha, \alpha$-diphenyl-2-pyrrolidine methanol trimethylsilyl ether in catalytic amounts using platinum electrodes under constant current in an undivided cell (Scheme 1a) [27]. Supported by control experiments and $\mathrm{CV}$, the authors suggested that the reaction proceeds via single-electron oxidation of the intermediate enamine, formed by dehydrative condensation between the substrate and pyrrolidine catalyst. The resulting cation radicals were trapped by TEMPO to form the oxyaminated products in 60-70\% ee, in accordance with the design principle in Figure 2a. As such, this study was the first to demonstrate that anodic oxidation could be used to promote 
enamine-mediated organocatalytic reactions via cationic radical enamine intermediates. A similar strategy was used by the same group for $\alpha$-alkylation of aldehydes with xanthene using chiral pyrrolidine catalysts in an undivided cell with platinum electrodes under constant current conditions (Scheme 1b) [28]. Supported by CV analysis and control experiments, the mechanism was proposed to proceed via single-electron oxidation of both the enamine and the xanthene, followed by radical coupling to afford the product in up to $74 \%$ yield and $70 \%$ ee (Figure 2a). However, as homocoupled products were not observed, a mechanism in accordance with the design principle of Figure $2 b$ proceeding via enamine attack of an electrochemically formed xanthene cation could not be excluded. This alternative activation mode was proposed by Jørgensen and co-workers for $\alpha$-arylation of aldehydes with $\mathrm{N}$-tosyl $p$-anisidine to form enantioenriched alcohols with $e e^{\prime}$ s up to $96 \%$ using (S)- $\alpha, \alpha$-diphenyl-2-pyrrolidine methanol trimethylsilyl ether as catalyst (10 mol\%) in an undivided cell with carbon anode and platinum cathode under constant current conditions (Scheme 1c) [29]. The authors suggested that electrochemical oxidation of the phenolic compound results in an electrophilic intermediate that is attacked by the chiral enamine, formed from the catalyst and the aldehyde substrate. Following the mechanistic rationale of traditional enamine catalysis, the resulting iminium ion is hydrolyzed to release the catalyst, which enters a new cycle, whereas the product would rearomatize and eventually cyclize to the corresponding dihydrobenzofuran.

Building on this initial work [27-29], Luo and co-workers utilized the enamine strategy for electrooxidative coupling of tertiary amines with ketones using a chiral diamine catalyst to obtain enantioenriched alkylated tetrahydroisoquinolines, using a graphite anode and Pt cathode in an undivided cell at constant potential (Scheme 2) [30]. No reaction was observed in the absence of either catalyst or current, and under optimized conditions the reaction proceeded with good to excellent enantioselectivities (up to $95 \%$ ee) and good yields for several N-arylated tetrahydroisoquinolines and ketones. The transformation was proposed to proceed via anodic oxidation of the benzylic position in the $\mathrm{N}$-aryl tetrahydroisoquinoline substrate to form an intermediate iminium ion (Scheme 2), in accordance with the design principle in Figure $2 \mathrm{~b}$. Subsequent attack by the chiral enamine, formed by dehydrative condensation of the catalyst and ketone substrate, results in the enantioenriched product in high yields and $e e^{\prime} \mathrm{s}$ after hydrolysis with release of the catalyst. The presence of a protonic additive $\left(\mathrm{CF}_{3} \mathrm{CH}_{2} \mathrm{OH}\right)$ was found to facilitate the $\mathrm{C}-\mathrm{C}$ bond formation, supposedly by capturing the iminium ion as a more stable hemiaminal intermediate. The proposed mechanism was supported by control experiments, where pre-oxidation of the tetrahydroisoquinoline substrate to the corresponding iminium ion and subsequent addition of catalyst/TfOH and ketone gave close to identical results compared to standard conditions. Furthermore, electroanalytic studies confirmed that preferential oxidation of the tetrahydroisoquinoline occurred in the reaction mixture.

The use of TEMPO and analogous N-oxide compounds as redox mediators in electrochemical oxidation of organic substrates is well-established. In several examples, chiral N-oxide derivatives were developed and afforded asymmetric electrochemical transformations such as the oxidative kinetic resolution of secondary alcohols and amines [31-39]. Similarly, asymmetric Cu-catalysis under electrooxidative conditions has been reported for kinetic resolution of 1, 2 diols, aminoalcohols and aminoaldehydes [40]. Mei and co-workers reported on a co-catalytic $\mathrm{Cu} / \mathrm{TEMPO}$ system for oxidative substitution of $\mathrm{N}$-aryl and $\mathrm{N}$-carbamate tetrahydroisoquinolines with terminal alkynes [41]. The use of TEMPO as redox mediator $(20 \mathrm{~mol} \%)$ and a $\mathrm{Cu}^{\mathrm{II}}$-species $(10 \mathrm{~mol} \%)$ with a chiral bisoxazoline ligand enabled good yields and up to $98 \%$ ee of the C1-alkynylated products under constant current conditions in an undivided cell using Pt electrodes (Scheme 3). The broad substrate scope demonstrated good functional group tolerance of the process and control experiments indicated that each reaction component was necessary for converting starting material into product. Based on CV measurements, the authors proposed that TEMPO acts as a redox mediator for Shono oxidation [42] of the tetrahydroisoquinoline to form the corresponding iminium species in benzylic position. Addition of the chiral copper acetylide, supposedly formed in situ from the $\mathrm{Cu}^{\mathrm{I}}$ catalyst and the alkyne in the presence of base, results in the enantioenriched product. As such, the authors propose a mechanism 
following the general principles of Figures $1 b$ and $2 b$, although alternative cooperative mechanisms involving both $\mathrm{Cu}$ and TEMPO were not ruled out. The active $\mathrm{Cu}^{\mathrm{I}}$ was suggested to form by interaction of $\mathrm{Cu}^{\mathrm{II}}$ with the reduced TEMPO mediator (TEMPO-H) or by cathodic reduction. A kinetic isotope effect study for the benzylic $\alpha$-hydrogens of the tetrahydroisoquinoline indicated $\mathrm{C}-\mathrm{H}$ cleavage is not rate-determining in the process.

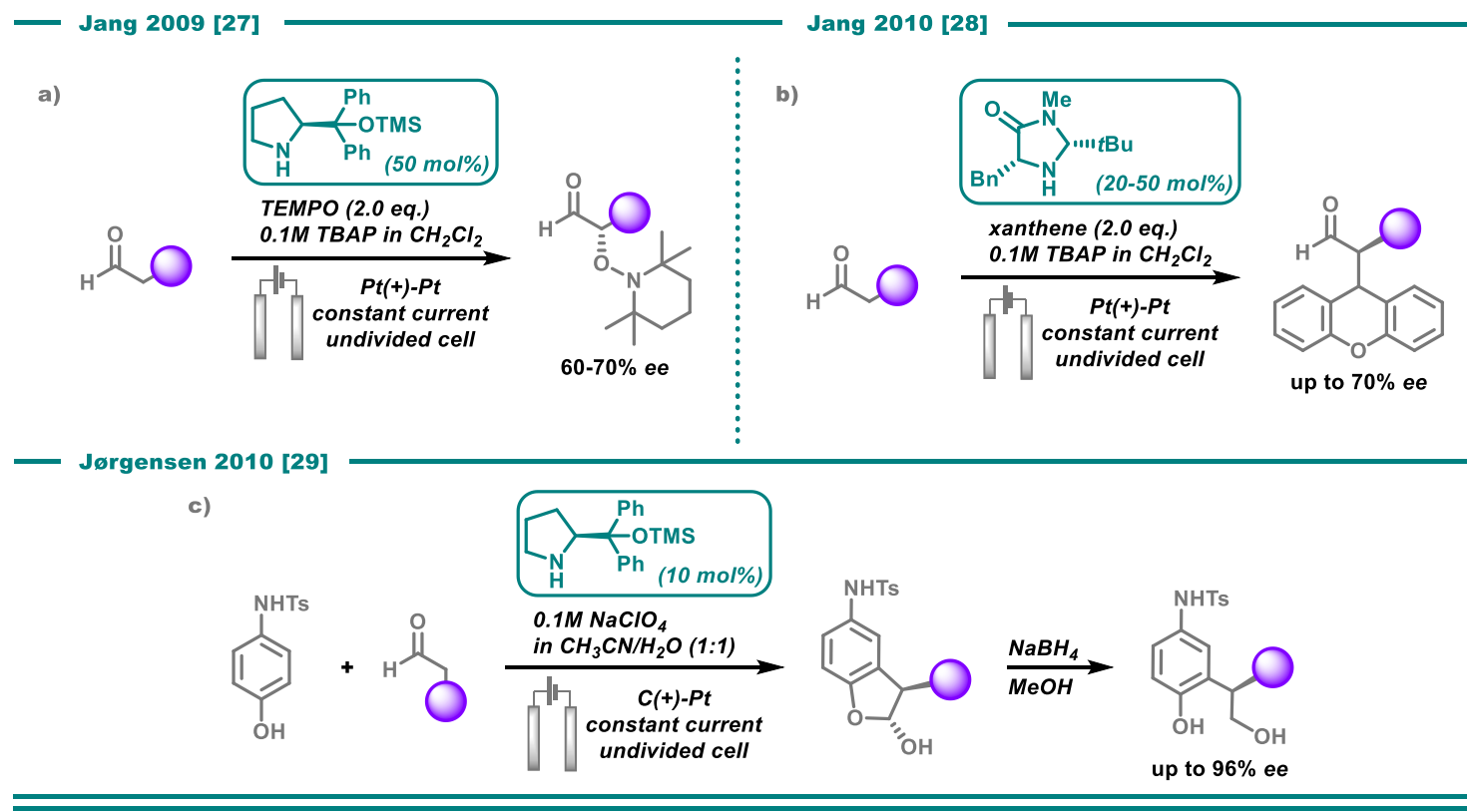

Scheme 1. (a) electrochemical organocatalytic $\alpha$-oxyamination of aldehydes; (b) electrochemical organocatalytic $\alpha$-alkylation of aldehydes; (c) electrochemical organocatalytic $\alpha$-arylation of aldehydes.

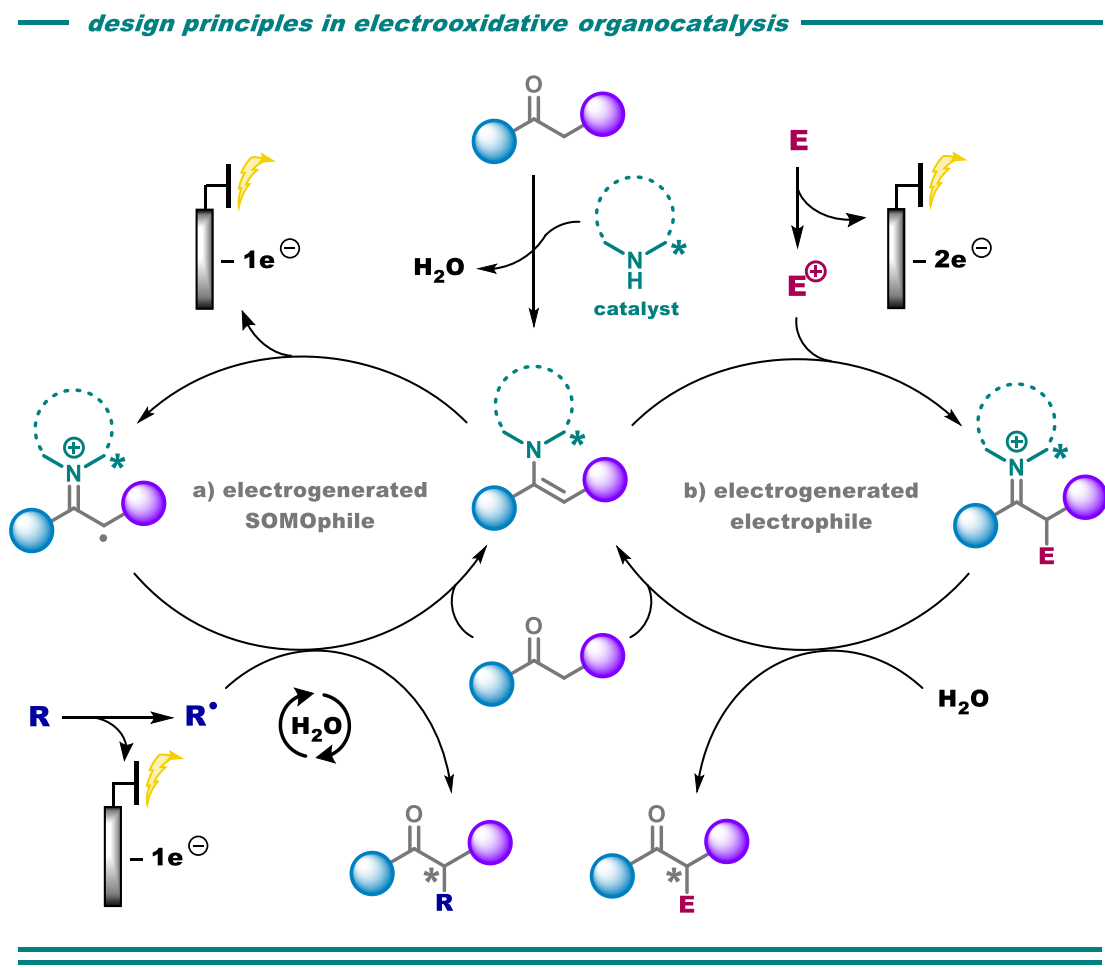

Figure 2. Two design principles for $\alpha$-functionalization of carbonyl compounds in electrooxidative enamine catalysis: (a) electrogenerated SOMOphile; (b) electrogenerated electrophile. 


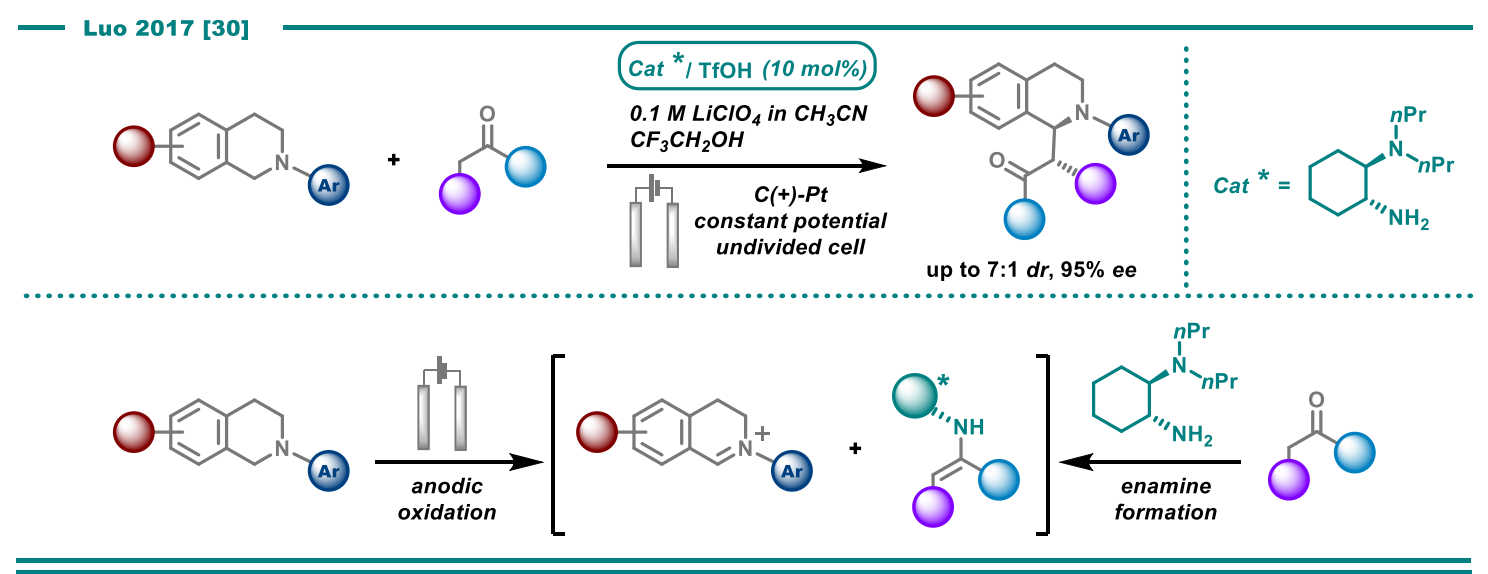

Scheme 2. Enantioselective organocatalytic coupling of tetrahydroisoquinolines and ketones under electrooxidative conditions.
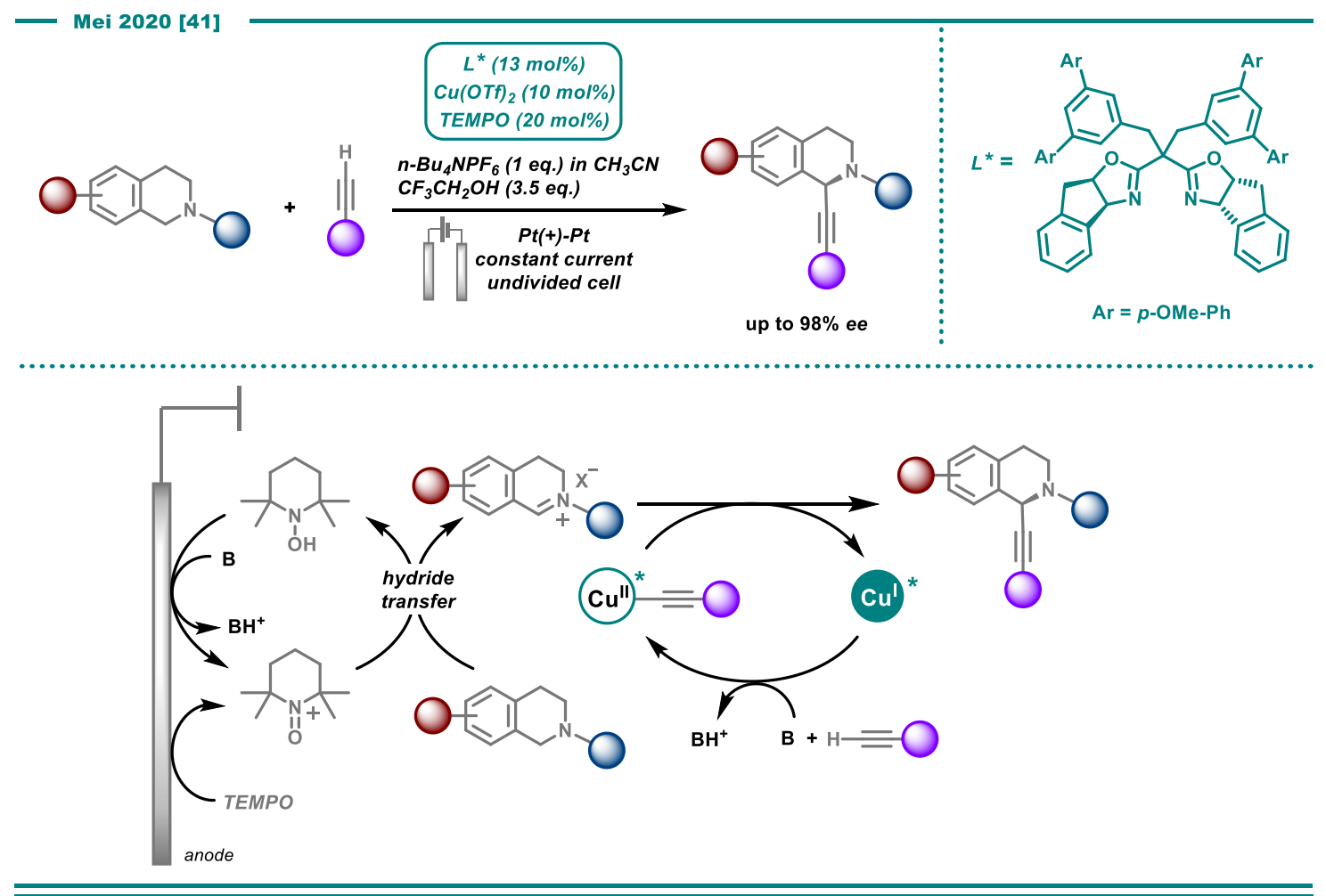

Scheme 3. $\mathrm{Cu}^{\mathrm{II}} / \mathrm{TEMPO}-\mathrm{catalyzed}$ enantioselective electrooxidative alkynylation of tetrahydroisoquinolines.

Guan, He and co-workers reported on the proline-catalyzed enantioselective synthesis of C2-quaternary indolin-3-ones from 2-arylindoles and ketones under electrochemical conditions (Scheme 4) [43]. The transformation was carried out in an undivided cell at constant current with $\mathrm{Pt}$ electrodes and resulted in moderate to good yields and excellent diastereo-and enantioselectivities (up to 99\% ee) of 2,2-disubstituted indol-3-one products bearing a quaternary stereocenter, an interesting compound class found in naturally occurring biologically active substances. The procedure was mostly found to be efficient on cyclic ketones, but two acyclic examples were also reported and could afford high ee's. Similar to the findings of Luo and co-workers [30], no reaction occurred in the absence of proline or electric current. In addition, no reaction was observed when starting from N-methyl-substituted indole. The reaction was proposed to proceed in accordance with the design principle in Figure $1 \mathrm{~b}$ via indirect oxidation of the indole to the corresponding radical cation, 
using TEMPO as redox mediator. Upon loss of a proton, the resulting indole radical was proposed to react with atmospheric oxygen after a hydrogen atom transfer (HAT). Subsequent attack of the imine carbon by the enamine, formed by the proline catalyst and the ketone substrate, results in the product after hydrolysis. Control experiments using isolated imine in the presence of the proline catalyst and ketone substrate under non-electrochemical conditions resulted in excellent yields and enantioselectivity and provided support for the proposed mechanism. Furthermore, the addition of BHT to standard conditions resulted in lower yields of the product as well as in the formation of a BHT adduct of the indole, detected by HRMS, thus indicating that a radical mechanism is operating. The use of ${ }^{18} \mathrm{O}$-labelled $\mathrm{O}_{2}$ and $\mathrm{H}_{2} \mathrm{O}$ indicated that the former was indeed the source of the incorporated oxygen, a hypothesis that was further strengthened by the greatly reduced yields observed when the reaction was performed under an Ar atmosphere. Benzoic acid was used as weakly acidic additive, which aided to increase the yield by facilitating enamine formation, an effect reported in various examples of asymmetric enamine catalysis [44]. The reaction was found to proceed in the absence of TEMPO with the same enantioselectivity but reaching lower yields. Based on CV analysis, the authors proposed that direct oxidation of the indole at the anode is occurring in the absence of TEMPO.

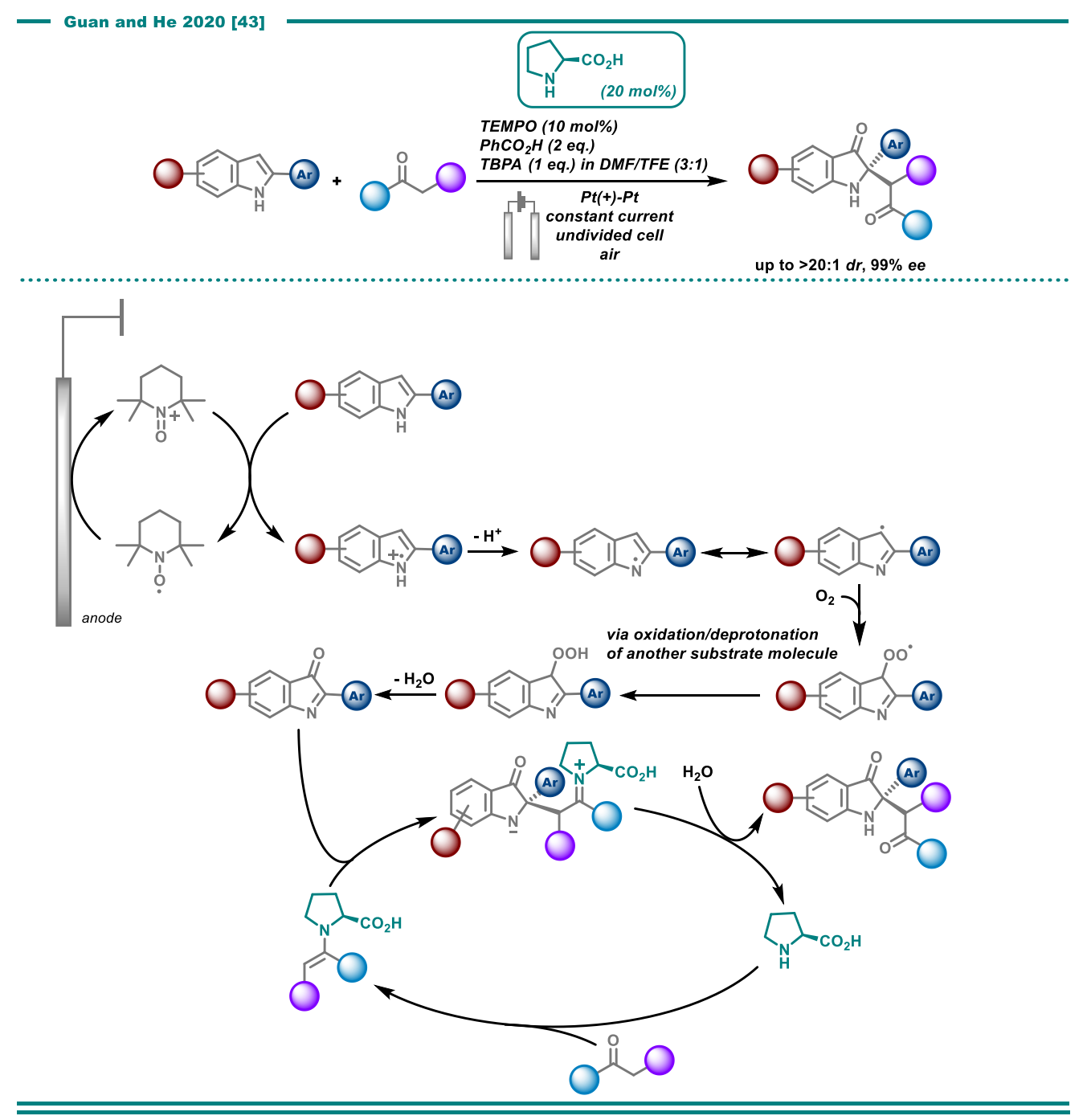

Scheme 4. Enantioselective proline-catalyzed electrosynthesis of C2-quaternary indolin-3-ones.

Luo and co-workers reported on the first asymmetric enamine-benzyne coupling (Scheme 5) [45]. Using a chiral diamine catalyst in an undivided cell with Pt electrodes and constant current conditions, $\alpha$-arylation of cyclic $\alpha$-ketocarbonyls with anodically formed benzyne occurred to form products with 
quaternary carbon stereocenters in good yields and with $e e^{\prime}$ s up to $99 \%$. Under the electrochemical conditions, 1-aminobenzotriazole could be used as benzyne precursor in the absence of the toxic oxidant $\mathrm{Pb}(\mathrm{OAc})_{4}$, typically required under non-electrochemical conditions [46-50]. In addition, the strategy was extended to the generation and use of cyclohexyne via the corresponding triazole precursor. Trapping experiments with tetraphenylcyclopentadienone under standard conditions resulted in good yields of the benzyne and cyclohexyne adducts but only trace amounts of the benchmark products, thus confirming the existence of the elusive intermediates. The substrate scope was limited to cyclic ketoesters and products were in some cases obtained as regioisomers, however all with high $e e^{\prime} \mathrm{s}$ and in moderate to good yields. No reaction was observed in the absence of the aminocatalyst, whereas results in the absence of electric current was not explicitly discussed. Experimentally, it was found that $\mathrm{Co}(\mathrm{OAc})_{2} \cdot 4 \mathrm{H}_{2} \mathrm{O}$ was beneficial as an additive $(20 \mathrm{~mol} \%)$ with a major effect on yield ( $71 \%$ vs. $28 \%$ ) and a minor effect on $e e(94 \%$ ee vs. $88 \%$ ee) of the product. With the use of CV, the authors found that the redox potentials of the Co salt and 1-aminobenzotriazole were comparable $\left(E_{\mathrm{ox}}=0.83\right.$ vs. $\left.0.84 \mathrm{~V}\right)$, hence suggesting that the Co salt was likely not functioning as a redox mediator for oxidative benzyne generation. However, control experiments with benzyne quenching reagents in the absence of $\alpha$-ketocarbonyl substrates resulted in rapid decomposition of the benzotriazole but only trace amounts of quenching adducts in the absence of the Co salt, whereas considerably higher yields were obtained in the presence of Co. Based on these findings, the authors proposed that the Co salt stabilizes the intermediate arynes by binding to the triple bond, thereby enhancing the propensity for enamine coupling. This hypothesis was supported by DTF calculations, indicating that coordination to Co acetate stabilizes benzyne by $18.6 \mathrm{kcal} / \mathrm{mol}$.

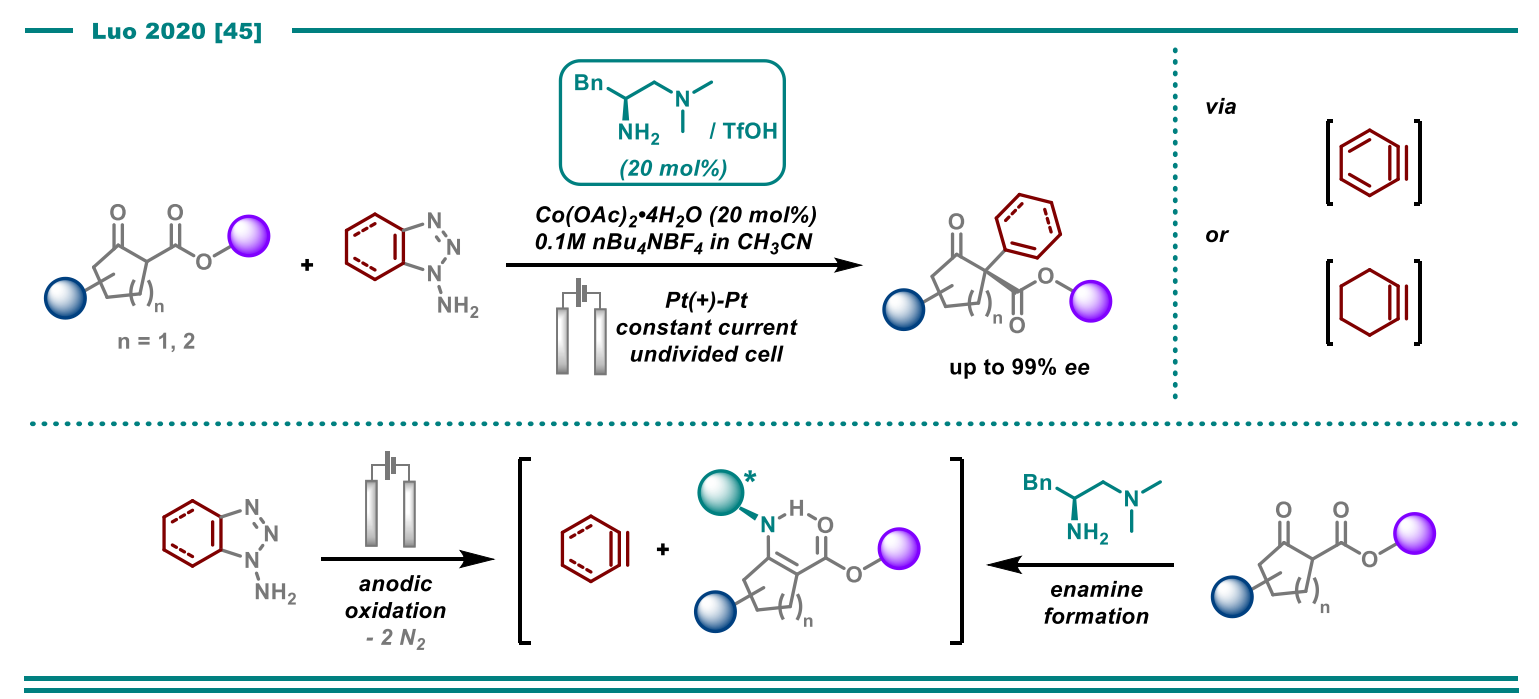

Scheme 5. Asymmetric catalytic $\alpha$-arylation of cyclic $\alpha$-ketocarbonyls with anodically formed benzyne or cyclohexyne.

Meggers and co-workers described an oxidative metal-catalyzed asymmetric $\mathrm{C}-\mathrm{H}$ functionalization of the $\alpha$-position of 2 -acyl imidazoles in an undivided cell equipped with a $C$ anode and Pt cathode under constant current conditions (Scheme 6) [51]. Using a chiral Lewis acidic Rh complex, 2-acyl imidazoles and silyl enol ethers were coupled to provide enantioenriched 1,4-dicarbonyls in up to $91 \%$ yield and $>99 \% e e$, including $>10$ examples of the formation of all-carbon quaternary stereocenters as well as two examples of complex natural product derivatization. Considerably lower yields were observed in the absence of a base, whereas only homocoupling of the silyl enol ether was obtained in the absence of the Rh catalyst. Mechanistically, the reaction was proposed to proceed via initial coordination of the 2-acyl imidazole substrate to the metal catalyst, followed by deprotonation by the external base (2,6-lutidine). The resulting Rh-coordinated enolate was envisioned to undergo anodic oxidation to afford a $\mathrm{C}$-centered radical in $\alpha$-position that would undergo stereocontrolled $\mathrm{C}-\mathrm{C}$ 
bond formation with the silyl enol ether and form a TMS-protected ketyl radical. A second anodic oxidation, followed by subsequent desilylation would close the catalytic cycle (Scheme 6). As presented, the anodic oxidations of the catalyst-bound substrate were envisioned as direct electrolysis events in accordance with the general principle in Figure 1a. The mechanistic proposal was supported by CV analysis, indicating that the Rh-bound 2-acyl imidazole has a considerably lower oxidation potential compared to the silyl enol ether and the unbound 2-acyl imidazole. Furthermore, control experiments using TEMPO as a radical quenching agent resulted in high yields of TEMPO-functionalized 2-acyl imidazole in $\alpha$-position, thus indicating that this carbon indeed hosts an intermediate radical.

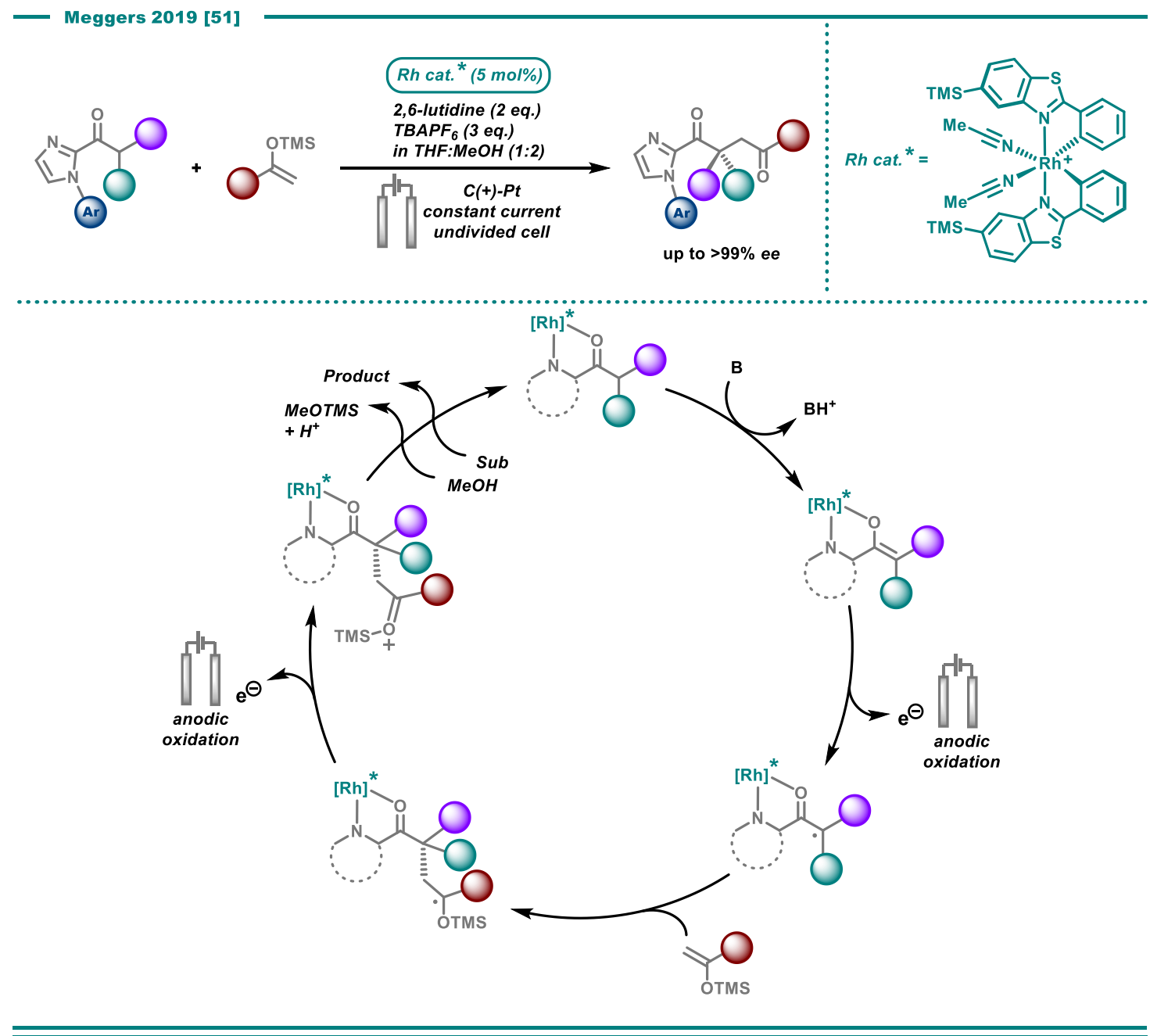

Scheme 6. Electrooxidative Lewis acid-catalyzed asymmetric cross-coupling of enolates.

Similar to the work of Meggers, Guo and co-workers reported the use of a Lewis acidic chiral $\mathrm{Ni}$ catalyst for enantioselective $\alpha$-benzylation of 2-acyl imidazoles with substituted hydroxytoluenes (Scheme 7) [52]. In an undivided cell at $0{ }^{\circ} \mathrm{C}$ using $\mathrm{C}$ electrodes at constant potential, electrochemical benzylation was carried out with good yields and excellent enantioselectivities (up to $97 \% e e$ ) in the presence of $\mathrm{Ni}(\mathrm{OAc})_{2}$, a chiral diamine ligand and base (quinuclidine). No product formed in the absence of either $\mathrm{Ni}$, diamine ligand or current, whereas the absence of base resulted in reduced yields but similar $e e$. Trapping experiments afforded $11 \%$ of the TEMPO adduct in $\alpha$-position to the 2-acyl imidazole, suggesting that a radical can form at this carbon. Furthermore, dimerization of the 1,4,6-trimethylphenol under different conditions indicated that an intermediate benzylic radical may also form. Based on the combined results from these studies as well as CV and electron paramagnetic resonance (EPR) spectroscopy, the authors proposed the mechanism found in Scheme 7. 
Initial coordination of the 2-acyl imidazole to the chiral Ni catalyst followed by deprotonation by the base affords the Ni-bound enolate. Anodic oxidation of this species affords the C-centered radical in $\alpha$-position to the coordinated carbonyl, which undergoes coupling with a benzylic radical, formed via anodic oxidation via a separate route. As such, a mechanism similar to that of electrogenerated SOMOphiles in enamine catalysis (Figure 2a) was proposed. The possibility of direct interaction between the benzylic radical and the Ni center that could result in product formation after reductive elimination was not discussed by the authors. While quinuclidine is a known HAT catalyst in photoredox catalysis [53-58], additional mechanistic roles of this base, e.g., assistance in the formation of the postulated benzylic radical coupling partner, were not proposed.
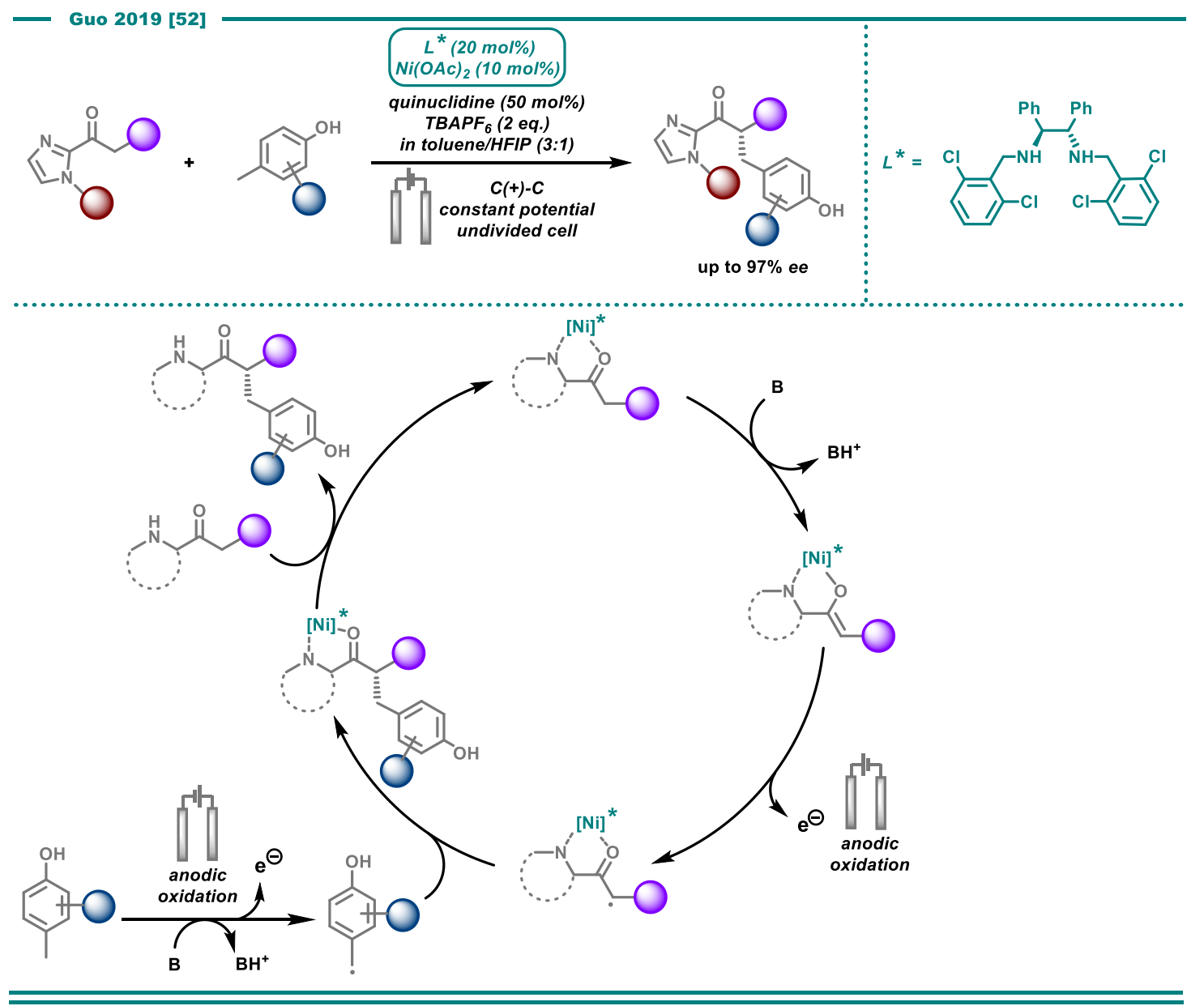

Scheme 7. Lewis acid-catalyzed electrooxidative enantioselective $\alpha$-benzylation of 2 -acyl imidazoles.

Along the same lines, the same group developed an enantioselective bifunctional squaramidecatalyzed detrifluoroacetylative alkylation reaction using substituted hydroxytoluenes under electrochemical conditions [59]. Using carbon electrodes under constant current conditions at $70{ }^{\circ} \mathrm{C}$, fluorine-containing compounds bearing stereocenters at the C-F bond were formed in good yields and $e e^{\prime}$ s up to $95 \%$. As suggested by the authors, the trifluoromethyl $\alpha$-fluorinated $\beta$-keto gem-diol substrate is activated by the squaramide catalyst and reacts with the electrochemically formed $p$-quinone methide (Scheme 8), as such resembling the principles of Figure $2 \mathrm{~b}$ with anodic electrophile formation. Base-induced detrifluoroacetylation followed by stereoselective proton transfer generates the product as the final step in the absence of electricity. 

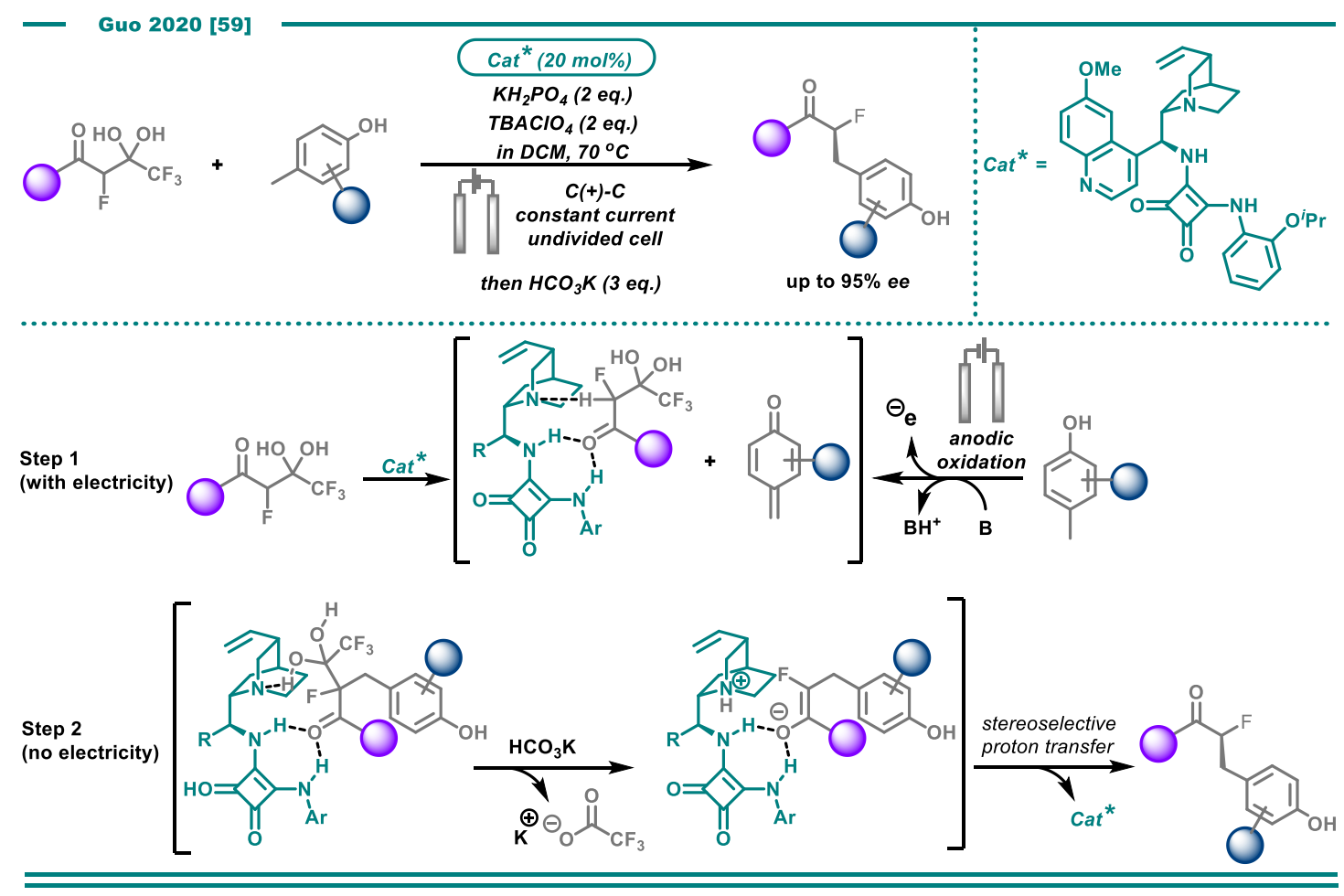

Scheme 8. Squaramide-catalyzed electrooxidative enantioselective $\alpha$-benzylation/detrifluoroacetylation of trifluoromethyl $\alpha$-fluorinated $\beta$-keto gem-diols.

Ackermann and co-workers demonstrated the first asymmetric electrooxidative $\mathrm{C}-\mathrm{H}$ activation process using $\mathrm{Pd}$-catalysis and L-tert-leucine as transient directing group to provide access to axially chiral biaryls (Scheme 9) [60]. In an undivided cell with graphite felt anode and Pt plate cathode and constant current at $60{ }^{\circ} \mathrm{C}$, various aldehyde-substituted biaryls were alkenylated to form axially chiral products in good yields with excellent $e e^{\prime}$ s (up to $99 \%$ ) and high position- and diastereocontrol. The substrate scope also included examples of $\mathrm{N}-\mathrm{C}$ axially chiral $\mathrm{N}$-aryl pyrroles and the use of perfluorinated alkenes. Furthermore, it was demonstrated how the axially chiral products could be converted into enantioenriched [5]-and [6]-helicenes, dicarboxylic acids and BINOL derivatives in high yields and optical purity. Control experiments revealed that no reaction occurred in the absence of either Pd catalyst or L-tert-leucine, whereas the absence of current resulted in considerably lower yield of the benchmark substrate ( $25 \%$ vs. $71 \%$ ). Labelling experiments indicated that $\mathrm{C}-\mathrm{H}$ activation is the rate-limiting step and that no $\mathrm{H} / \mathrm{D}$ scrambling occurs between the substrate and the acetic acid solvent. Furthermore, a non-linear-effect (NLE) was not observed, indicating that the reaction proceeds with a metal to ligand ratio of 1:1 in the enantiodetermining step.

With the aid of DFT calculations, the authors proposed a Pd ${ }^{\mathrm{II}}$-mechanism where initial imine formation between the leucine ligand and the aldehyde substrate results in a transient directing group that facilitates the asymmetric $\mathrm{Pd}$-catalyzed $\mathrm{C}\left(\mathrm{sp}^{2}\right)-\mathrm{H}$ activation. The nature of the transition state for this step was not discussed by the authors. Based on the presented geometry-optimized structures of intermediates, it does however appear as if the $\mathrm{C}-\mathrm{H}$ bond breakage is envisioned to occur with the aid of an acetate base. The resulting $\mathrm{Pd}^{\mathrm{II}}$ species coordinates an alkene reactant, followed by its insertion into the $\mathrm{Pd}-\mathrm{C}$ bond. Although not explicitly mentioned, it can be envisioned that $\beta$-hydride elimination followed by hydrolysis of the transient imine releases the product. The role of the electricity was not specifically discussed by the authors. However, as the control reaction without current resulted in a product yield corresponding to more than two catalyst turnovers, it appears as if electricity is accelerating product formation rather than enabling it. 


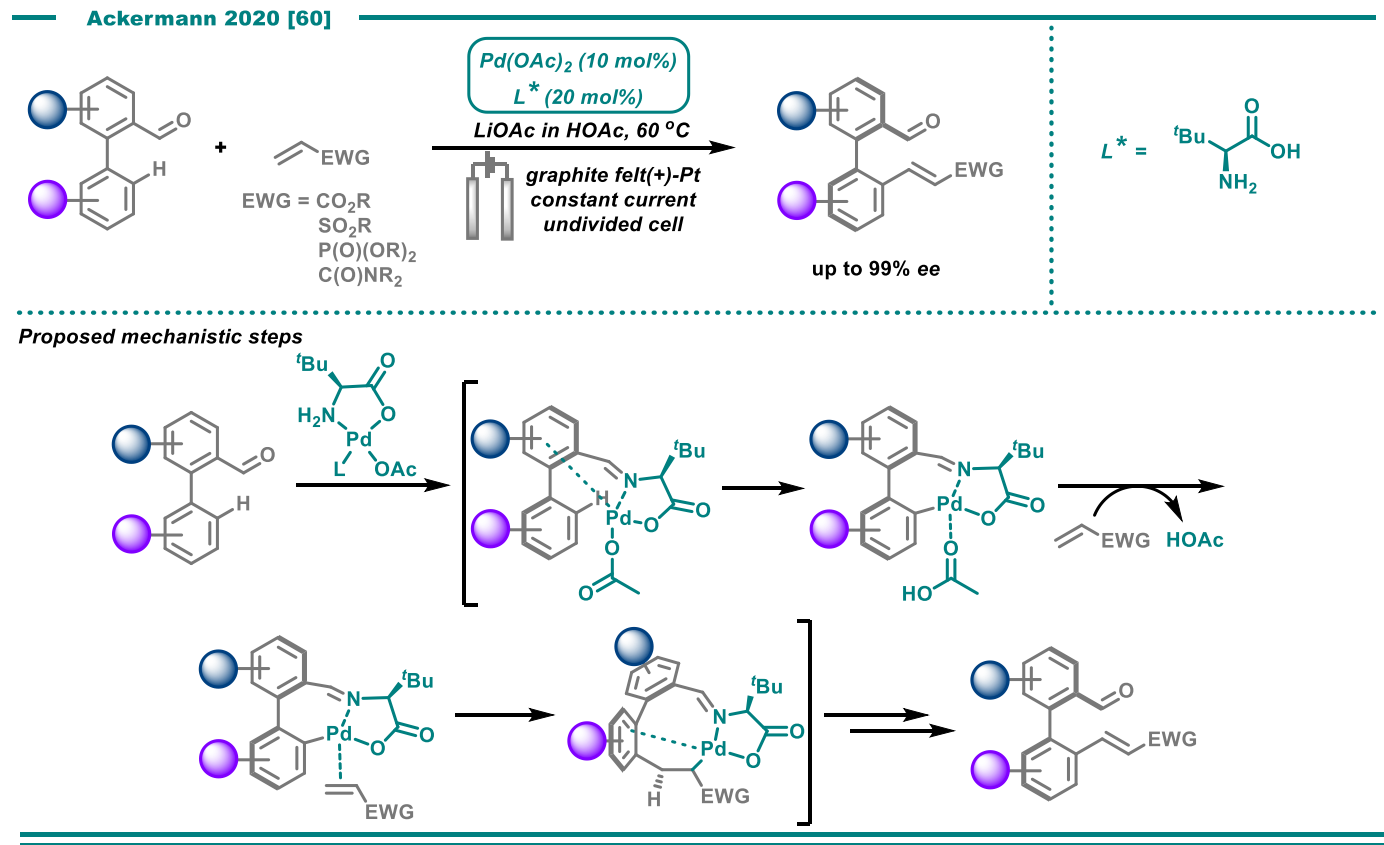

Scheme 9. Palladium-catalyzed C-H activation with a transient directing group under electrochemical conditions.

\subsection{Alkene Functionalization}

The prochiral nature of alkenes makes them excellent starting materials for asymmetric synthesis. A classic asymmetric oxidative transformation of alkenes is the Sharpless dihydroxylation using osmium catalysis in conjunction with chiral amine ligands and a stoichiometric oxidant [61-63]. As reported by Tsuji and Sharpless in the early 1990 's, potassium ferricyanide $\left[\mathrm{K}_{3} \mathrm{Fe}(\mathrm{CN})_{6}\right]$ can efficiently reoxidize an Os catalyst back to the active +8 state [64-66]. In the original Sharpless procedure, 3 equivalents of the ferricyanide salt were added to enable good turnover for the asymmetric dihydroxylation with excellent $e e^{\prime}$ s. Making use of anodic regeneration, Amundsen and Balko were able to reduce the stoichiometry to 0.4 equivalents using coupled redox cycles (Figure 3) in a divided cell with Pt electrodes at constant potential [67]. Similar to the Sharpless protocol, the authors used a biphasic mixture with the Fe salt in the aqueous phase and the organic transformation occurring in the organic phase, with re-oxidation of the Os catalyst taking place at the solvent interface. With an analogous approach, Torii et al. were able to further reduce the loading of both $\mathrm{Os}$ and $\mathrm{K}_{3} \mathrm{Fe}(\mathrm{CN})_{6}$ using an undivided cell with Pt electrodes at constant current conditions at $0{ }^{\circ} \mathrm{C}$ [68]. In addition, Torii et al. developed an electrochemical iodine-assisted asymmetric dihydroxylation under similar electrochemical conditions, replacing ferricyanide with substoichiometric $\mathrm{I}_{2}$ as co-oxidant. As pointed out by the authors, although the $\mathrm{Os}^{\mathrm{IV}}$ complex could be directly oxidized at the anode, mediated electrolysis in solution is preferred as direct oxidation can lead to catalyst adsorption on the electrode surface that may inhibit catalysis [69].

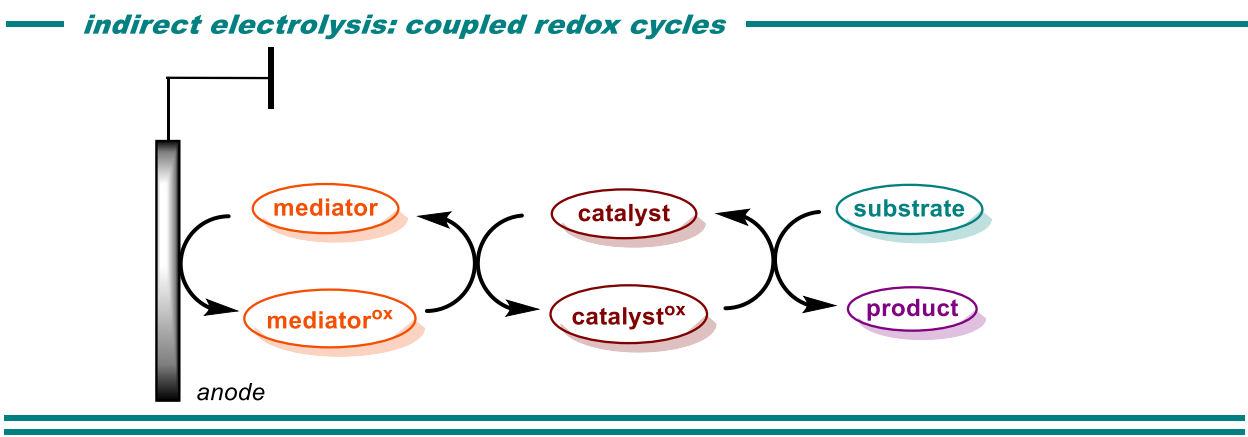

Figure 3. Principle for indirect oxidative electrolysis using coupled redox cycles. 
Using the same principle of electrochemically driven coupled redox cycles, Torii and co-workers developed a protocol using anodically generated chloronium oxidants for olefin epoxidation [70], inspired by the Katsuki-Jacobsen epoxidation [71-73]. With an optically active Mn-salen complex $\left(5 \mathrm{~mol} \%\right.$ ) in an undivided cell and Pt electrodes at $0{ }^{\circ} \mathrm{C}$ under constant current conditions in biphasic media, a handful of substrates were converted to the corresponding epoxides in up to $93 \%$ yield and $87 \%$ ee. According to the authors, chloride ions were oxidized in the aqueous phase to chloronium species that subsequently entered the organic phase to oxidize the Mn catalyst, thereby driving the oxidation process forward. Along the same lines, Bethell and co-workers utilized electrogenerated percarbonate and persulfate oxidants for iminium catalyzed epoxidation of alkenes with moderate enantiomeric excess (up to $64 \%$ ee), using a boron-doped diamond anode and Pt wire cathode in an undivided cell under constant current conditions [74]. In recent years, asymmetric electrochemical Os-catalyzed dihydroxylation and Mn-catalyzed epoxidation have been demonstrated to work well on a photovoltaic platform for improved process sustainability (Scheme 10) [75,76].

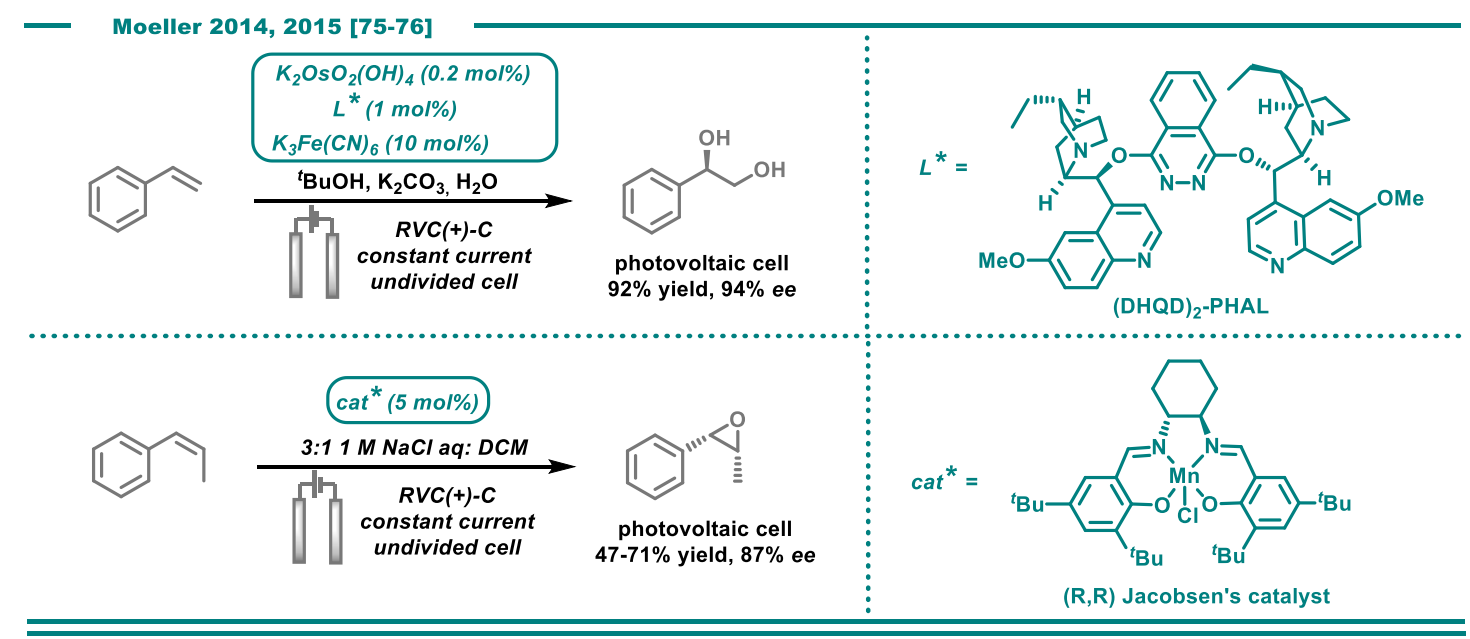

Scheme 10. Indirect electrooxidation of alkenes using coupled redox cycles in a photovoltaic system.

Lin and co-workers described enantioselective cyanophosphinoylation and cyanosulfinylation of alkenes in an anodically driven electrochemical process, using a copper catalyst with a newly developed serine-derived bisoxazoline ligand (Scheme 11) [77]. With a carbon felt anode and $\mathrm{Pt}$ cathode in an undivided cell under constant current conditions at $0{ }^{\circ} \mathrm{C}$, a variety of styrene derivatives were functionalized in moderate to good yields with $e e^{\prime}$ s up to $95 \%$ (cyanophosphinoylation) and $98 \%$ (cyanosulfinylation), including heterocyclic substrates and substrates with functional groups sensitive to oxidation such as aldehyde and sulfide. The authors proposed that the electric current is required to oxidize the $\mathrm{Cu}$ catalyst from oxidation state +1 to its catalytically active +2 state. In its activated state, the copper catalyst was claimed to have a dual role (Scheme 11). Initially, the $\mathrm{Cu}^{\mathrm{II}}$ catalyst was envisioned to oxidize a secondary phosphine oxide to its corresponding radical. This would in turn attack the alkene substrate to form an intermediate with the resulting radical situated in the stabilized benzylic position. Secondly, the reduced $\mathrm{Cu}$ catalyst would undergo another anodic oxidation event to form once more the active $\mathrm{Cu}^{\mathrm{II}}$ complex. The active complex would thereafter accommodate the benzylic radical intermediate and form the enantiomerically enriched product upon reductive elimination. As such, the $\mathrm{Cu}$ catalyst is envisioned to act as a redox mediator in the first step in accordance with the general principle in Figure $1 b$, whereas it acts as an enantioselective cross-coupling catalyst in an electrochemically driven redox cycle in the second step (Figure 1c). Based on the assumption of a $\mathrm{Cu}^{\mathrm{III}}$ intermediate, optimization of the ligand structure was carried out by adding ancillary ester groups to the bisoxazoline (BOX) scaffold to stabilize the high-valent intermediate prior to reductive elimination. In addition, it was hypothesized that this modification would allow for a more rigid structure that could improve selectivity in the enantio-determining step, 
as well as prevent cathodic demetalation of the catalyst. With the new ligand, an increase in $e e$ from $84 \%$ to $95 \%$ was observed for the benchmark substrate.

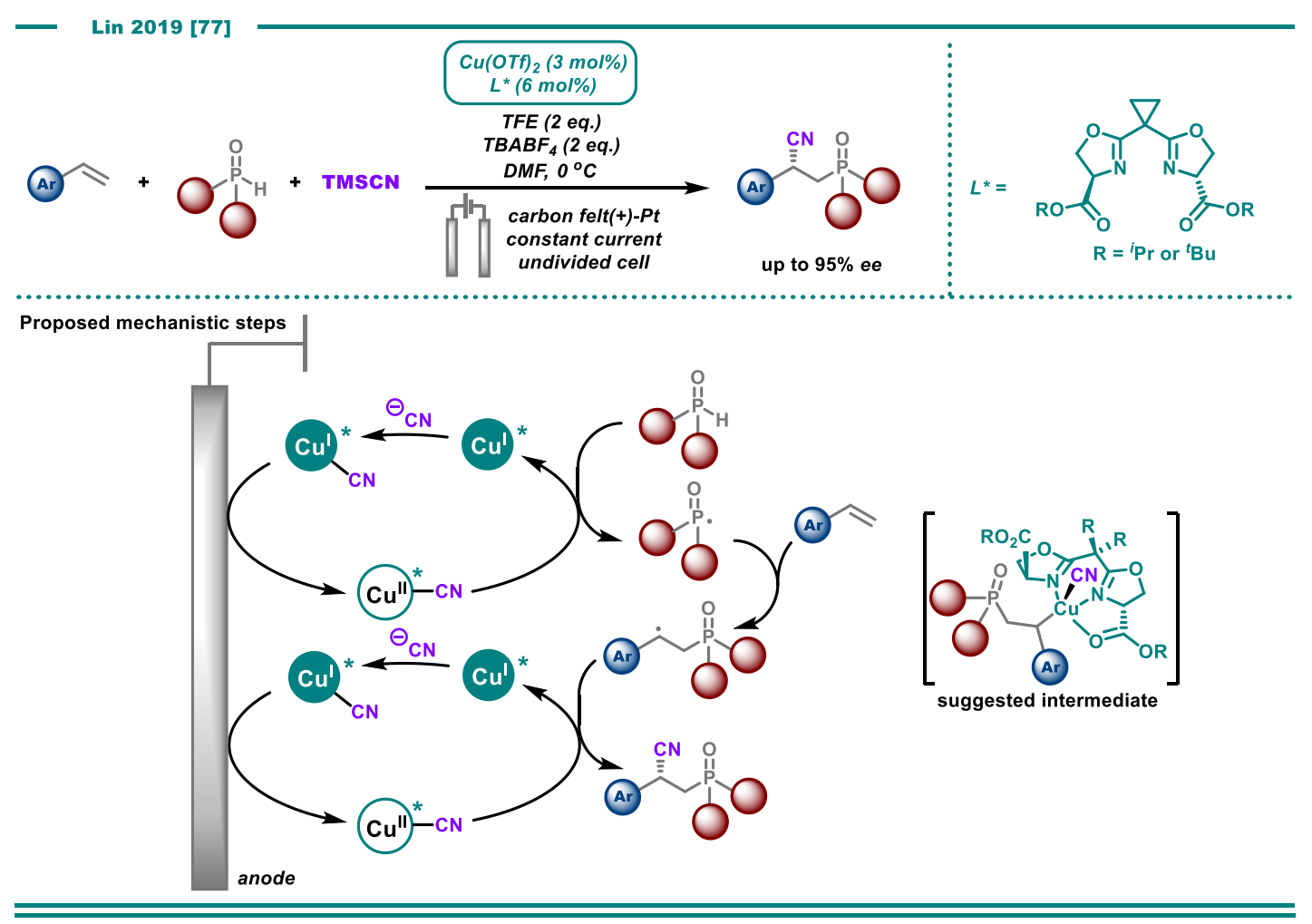

Scheme 11. Copper-catalyzed asymmetric oxidative difunctionalization of alkenes.

Along the same lines, the Lin group published a second anodically driven enantioselective functionalization of alkenes [78]. In conjunction with a cobalt(salen) complex, the use of the same type of asymmetric $\mathrm{Cu}$ catalyst as in their prior work enabled hydrocyanation of differently substituted olefins using $\mathrm{PhSiH}_{3}$ and TMSCN in an undivided cell at $0{ }^{\circ} \mathrm{C}$ and constant potential, equipped with a carbon anode and $\mathrm{Pt}$ cathode (Scheme 12). A range of terminal and internal alkenes were transformed into their corresponding hydrocyanated products with high enantioselectivity $(80-95 \% e e)$. Dienes, enynes and allenes were also compatible substrates, with terminal bonds being favored sites for hydrocyanation. In the case of allenes, excess reagents allowed for dicyanation. A comparison between the developed electrochemical protocol and the use of several chemical oxidants indicated that anodic oxidation resulted in the best yields and enantioselectivities under the examined conditions. Acetic acid was used as an additive in the transformation, rationalized as preventing undesired cathodic reduction of the $\mathrm{Cu}$ catalyst.

The suggested mechanism for the transformation resembles that proposed for the Lin group's preceding work on $\mathrm{Cu}$-catalyzed alkene functionalization in Scheme 11 [77]. The first anodic event leads to the formation of a C-centered radical and the second anodic event produces the active asymmetric $\mathrm{Cu}^{\mathrm{II}}$ cross-coupling catalyst that reacts with the $\mathrm{C}$-centered radical and forms product upon reductive elimination. For the hydrocyanation reaction, the initial anodic oxidation step was proposed to involve electrochemical oxidation of the $\mathrm{Co}^{\mathrm{II}}$ catalyst, followed by the formation of a cobalt hydride species upon reaction with the hydrosilane reagent. Hydrogen atom transfer of this metal hydride to the alkene would result in a C-centered radical that in turn reacts with the asymmetric $\mathrm{Cu}$-catalyst and eventually forms product. As such, both electrochemical processes appear to follow the general principle of Figure 1c. A radical rearrangement experiment provided support for the notion of intermediate radicals, whereas DFT calculations suggested that the enantio-determining $\mathrm{C}-\mathrm{CN}$ bond formation was the turnover-limiting step of the process. 


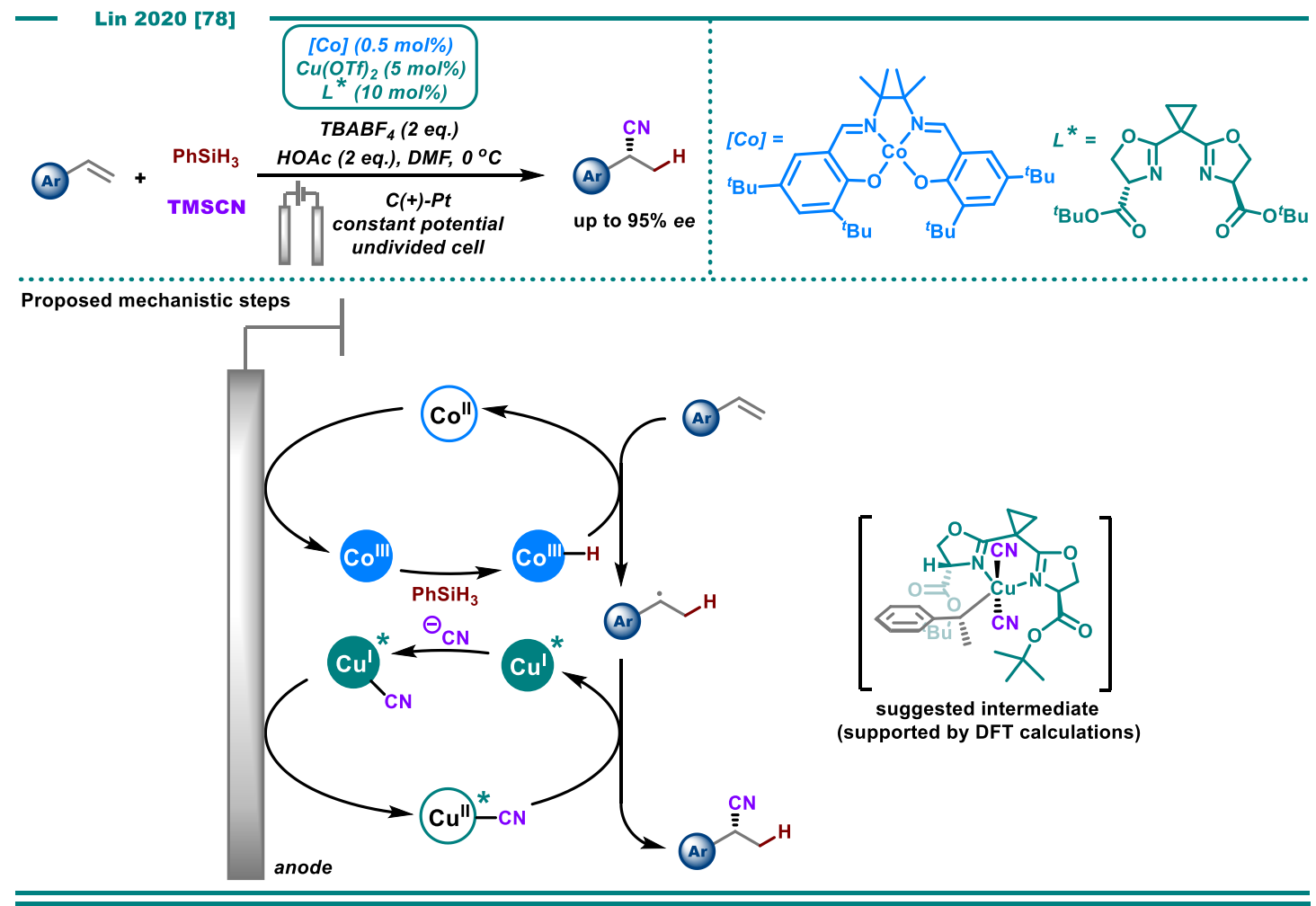

Scheme 12. Anodically driven asymmetric hydrocyanation of alkenes by $\mathrm{Co} / \mathrm{Cu}$ catalysis.

\section{Reductive Transformations}

Reductive organocatalytic electrosynthesis dates back to the late 1960s, when Grimshaw and co-workers described the use of alkaloids in catalytic amounts for the reduction of 4-methylcoumarins to optically active 3,4-dihydro-4-methylcoumarins in a divided cell at constant potential [79,80]. The transformation resulted in only modest chiral induction and moderate yields, the latter due to competing dimerization of the intermediate coumarin radical. Nevertheless, the organocatalytic strategy inspired the work of other groups working in this field [81-83] and chiral amines have been used as additives in catalytic amounts for asymmetric reduction of various ketones, carboxylic acids and oximes as well as for reductive dehalogenation [84-97]. Electrocatalytic reductions have also been carried out using metal catalysts, including a $\mathrm{Rh}^{\mathrm{III}}$ polypyridyl complex for the hydrogenation of acetophenone with modest chiral induction [98]. Other early electroreductive metal-catalyzed enantioselective processes include cobalt catalysis in the form of vitamin $B_{12}$ [99-101], as well as nickel catalysis [102] for dehalogenations, isomerizations, reductive cleavages, etc.

\subsection{Carboxylation Using $\mathrm{CO}_{2}$}

The electroreductive use of carbon dioxide $\left(\mathrm{CO}_{2}\right)$ as a $\mathrm{C} 1$ synthon is a strategy that receives continued interest for direct reduction to fuels and bulk chemicals, as well as for incorporation in more complex organic molecules [103-107]. In the context of asymmetric electrosynthesis, both organocatalytic and metal-catalyzed examples can be found. In similarity with the early asymmetric electroreductive protocols, alkaloids have found their use in asymmetric electroreductive carboxylation of ketones with carbon dioxide. Lu and co-workers utilized catalytic amounts of cinchonidine and cinchonine to form $(R)$-or $(S)$-atrolactic acid with $e e^{\prime}$ s up to $30 \%$, respectively, using a stainless steel cathode and $\mathrm{Mg}$ sacrificial anode in an undivided cell and constant current conditions [108]. Furthermore, cinchonine was used in catalytic amounts for the electrocarboxylation of 4-methylpropiophenone to form the (S)-configured product (up to 33\% ee), using a similar experimental setup [109]. A few years later, the same group reported moderate yields and ee's (up to 49\% ee) 
in the electrocarboxylation of 2-acetonaphthone under constant current conditions, using $2.5 \mathrm{~mol} \%$ of cinchonidine with a sacrificial $\mathrm{Mg}$ anode and stainless steel cathode in an undivided cell under atmospheric $\mathrm{CO}_{2}$ pressure at $0{ }^{\circ} \mathrm{C}$ [110]. In successive work, the group utilized a metal-catalyzed strategy for the electrocarboxylation of 1-phenylethyl chloride, employing a $\mathrm{Co}^{\mathrm{II}}$-(R,R)(salen) complex (15 mol\%) [111]. Optically active 2-phenylpropionic acid could be obtained in $37 \%$ yield and $83 \%$ ee under potentiostatic conditions in an undivided cell with glassy carbon cathode and $\mathrm{Mg}$ anode at $50{ }^{\circ} \mathrm{C}$ (Scheme 13), while no reaction was observed in absence of a Co source. With the support of $\mathrm{CV}$ analysis, the transformation was proposed to proceed via one-electron transfer to give an anionic $\left[\mathrm{Co}^{\mathrm{I}}-(\mathrm{R}, \mathrm{R})(\right.$ salen $\left.)\right]$ complex, which could react with the substrate to form a $\mathrm{Co}^{\mathrm{III}}$ organocobalt intermediate. One-electron reduction of this species to a $\mathrm{Co}^{\mathrm{II}}$ anionic complex followed by direct nucleophilic attack to $\mathrm{CO}_{2}$ ensures the asymmetric induction. However, if homolytic cleavage of the Co- $\mathrm{R}$ bond occurs, the generated $\left[\mathrm{PhCH}(\mathrm{CH})_{3}\right]$ radical can prompt a competing background reaction (upon reduction to the corresponding anion and attack to $\mathrm{CO}_{2}$ ) to give the racemic acid. Detection of styrene by GC-MS and the observation of dimer as major side-product supported the proposed formation of radical intermediates.

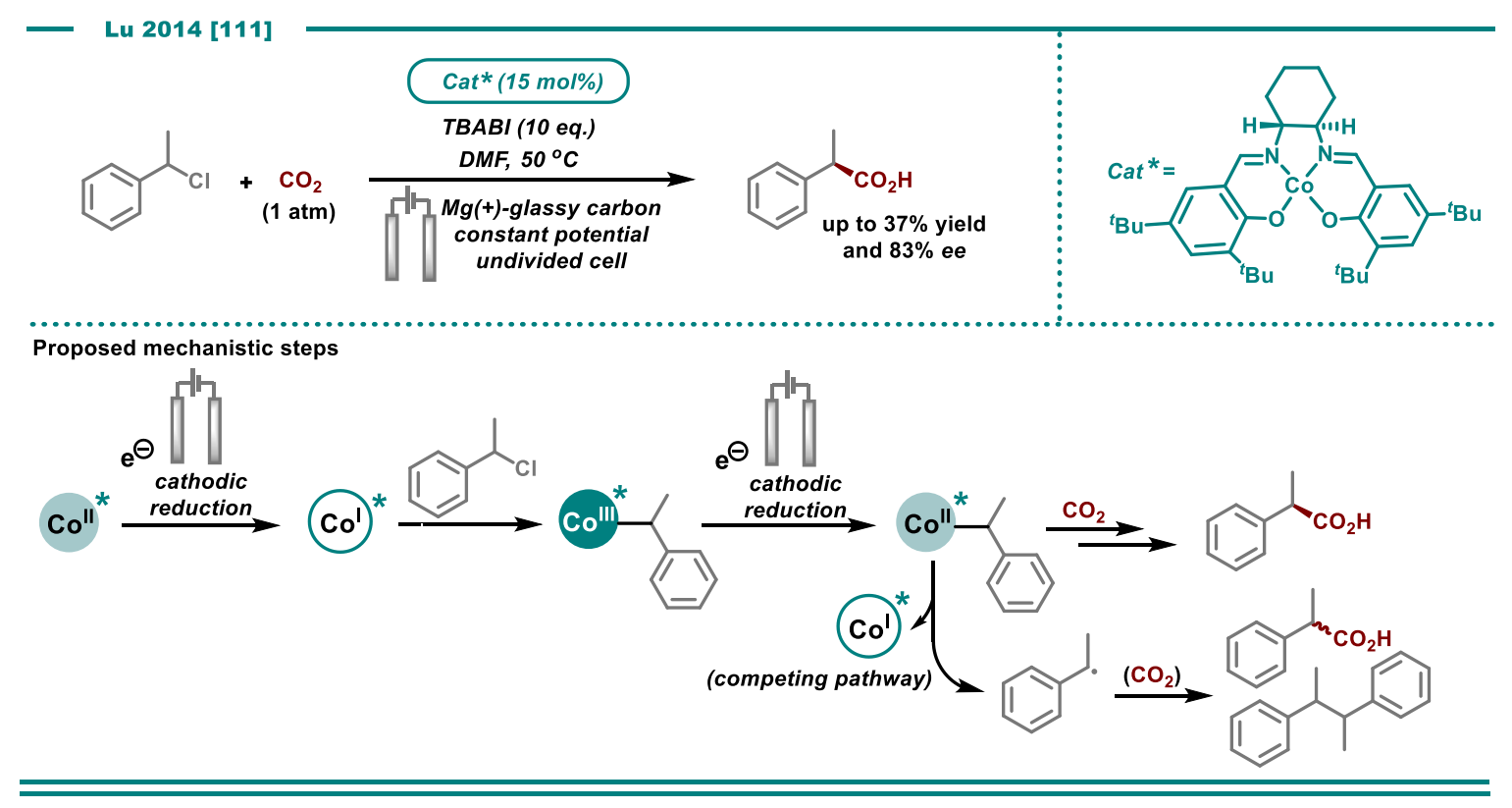

Scheme 13. Cobalt-catalyzed reductive carboxylation of benzylic chlorides.

In 2018, Mei and co-workers developed a Pd-catalyzed electrocarboxylation of allyl esters, providing $\alpha$-aryl carboxylic acids in high yields and regioselectivity [112]. In the report, the enantioselective variant of the method was developed using $\mathrm{Pd}(\mathrm{OAc})_{2}(7.5 \mathrm{~mol} \%)$ in combination with a chiral bidentate triarylphosphine ligand $(8 \mathrm{~mol} \%)$ under constant current in an undivided cell with a Pt cathode and a $\mathrm{Mg}$ sacrificial anode, under 1 atmosphere of $\mathrm{CO}_{2}$. Moderate yield $(66 \%)$ and enantioselectivity $(67 \%$ ee) could be obtained (Scheme 14). No reaction was observed when the current was replaced with common chemical reductants as $\mathrm{Mn}^{0}$ or $\mathrm{Zn}^{0}$, whereas the reaction proceeded even in the absence of the Pd catalyst, albeit with low conversion. The use of EtOH as an additive was crucial to grant higher yields and regioselectivities, although further insight about its role was not disclosed. Based on CV measurements, the authors proposed that initial reduction of $\mathrm{Pd}^{\mathrm{II}}$ to $\mathrm{Pd}^{0}$ followed by oxidative addition of the allyl acetate generates a cationic $\pi$-allylpalladium ${ }^{\mathrm{II}}$ complex. This species equilibrates to the favored terminal $\eta 1$-allylpalladium ${ }^{\mathrm{II}}$ species, which is reduced at the cathode. The resulting nucleophilic $\mathrm{Pd}^{0}$ complex reacts with $\mathrm{CO}_{2}$ to form a magnesium carboxylate salt with $\mathrm{Mg}^{2+}$ from the anode, while $\mathrm{Pd}^{0}$ re-enters the catalytic cycle. Direct attack of the $\eta 1$-allylpalladium ${ }^{\mathrm{II}}$ species to $\mathrm{CO}_{2}$ was ruled out since the transformation did not occur in absence of electric current. 


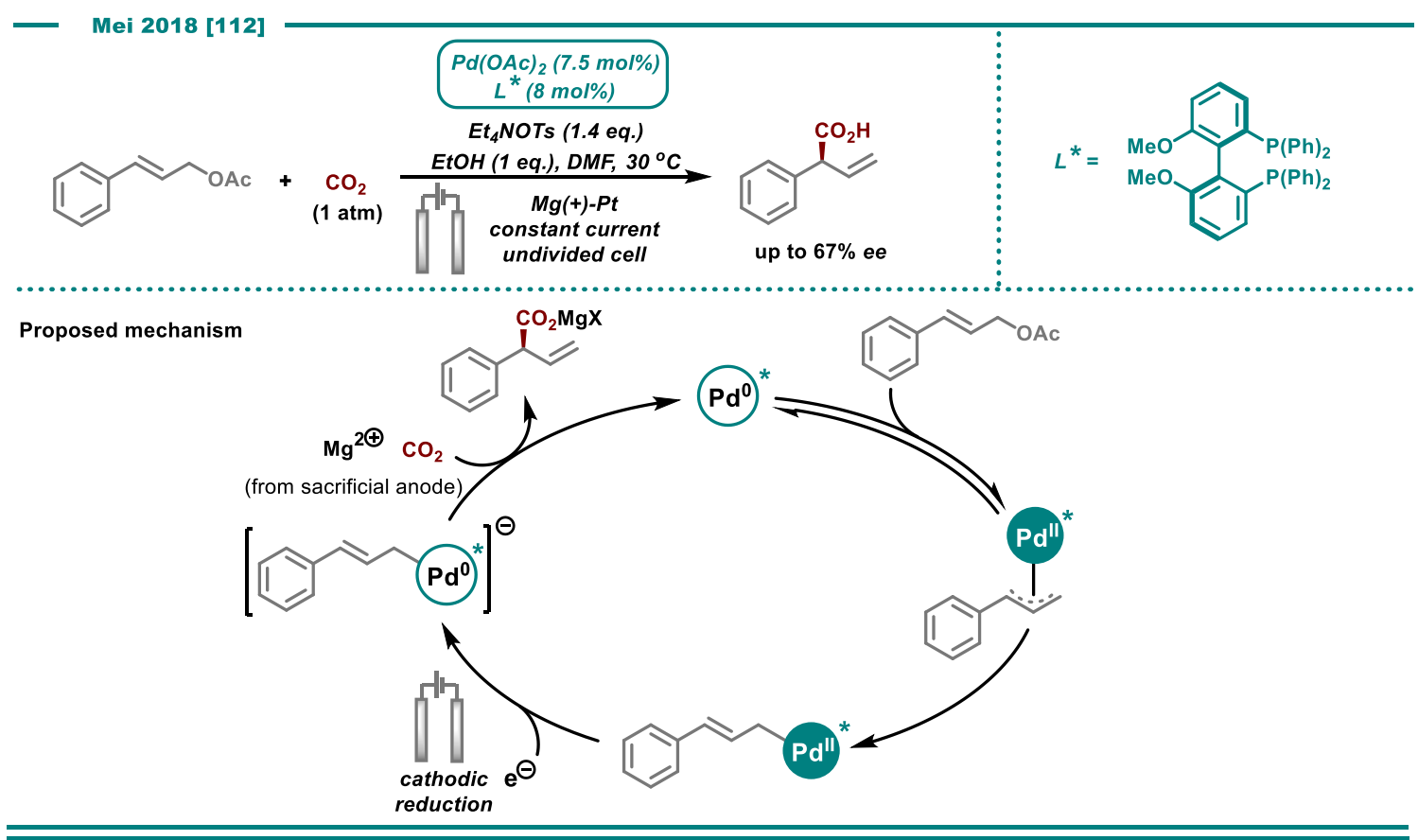

Scheme 14. Cathodically driven Pd-catalyzed carboxylation of cinnamyl acetate.

\subsection{Cross-Electrophile Couplings}

Reductive dehalogenation is a classic transformation in electrosynthesis [113] that includes stereoselective examples using cobalt catalysis $[99,100]$. The principle is relevant for transition metal-catalyzed reductive cross-electrophile couplings [114-116], and an enantioselective coupling of alkenyl and benzyl halides using a chiral Ni catalyst was demonstrated by Reisman and co-workers under electrochemical conditions [117]. Electrochemical catalyst activation and turnover granted $\mathrm{C}\left(\mathrm{sp}^{2}\right)-\mathrm{C}\left(\mathrm{sp}^{3}\right)$ bond formation without the need for sensitive organometallic reagents or metal powder reductants, and products bearing allyl stereocenters were obtained under mild conditions. $\mathrm{NiCl}_{2} \mathrm{dme}$ (10 $\mathrm{mol} \%)$ was employed as catalyst precursor together with an indanyl-substituted bisoxazoline ligand (20 $\mathrm{mol} \%$ ) in the presence of $\mathrm{NaI}$ in an undivided cell with a reticulated vitreous carbon (RVC) cathode and a $\mathrm{Zn}$ sacrificial anode at $0{ }^{\circ} \mathrm{C}$, furnishing the products in good yields and high $e e^{\prime} \mathrm{s}$ (up to $95 \%$ ) (Scheme 15). Control experiments confirmed that all components (Ni, ligand, current, additive) were essential for the reaction outcome. Although not specifically discussed in the paper, the cross-coupling has been considered to follow a sequential reduction mechanism $[118,119]$ taking into account results that proved inconsistent with a radical chain mechanism for the non-electrochemically-driven variant of the reaction [120]. In the sequential reduction pathway, a $\mathrm{Ni}^{0}$ complex would be generated from electroreduction of the $\mathrm{Ni}^{\mathrm{iI}}$ precursor, and the $\mathrm{C}\left(\mathrm{sp}^{2}\right)$ coupling partner (the alkenyl bromide) would undergo oxidative addition with this $\mathrm{Ni}^{0}$ species. The resulting $\mathrm{Ni}^{\mathrm{II}}$ intermediate is reduced at the cathode to a $\mathrm{Ni}^{\mathrm{I}}$ intermediate with concomitant loss of halide, while the following oxidative addition (of the racemic benzyl chloride) was defined as the stereoconvergent step. Upon reductive elimination, the $\mathrm{Ni}^{\mathrm{III}}$ complex is envisioned to liberate the enantioenriched product and forms a $\mathrm{Ni}^{\mathrm{I}}-\mathrm{Cl}$ species, which is again reduced to $\mathrm{Ni}^{0}$ to allow for catalyst turnover.

Another asymmetric cross-electrophile coupling was reported by Mei and co-workers to afford enantioselective electrochemical homocoupling of aryl bromides to axially chiral biaryls [121]. By the use of $10 \mathrm{~mol} \% \mathrm{NiCl}_{2}$.glyme with chiral pyridine-oxazoline ligands in presence of $\mathrm{NaI}$ and $4 \mathrm{~A}$ molecular sieves in an undivided cell equipped with a Ni cathode and a sacrificial $\mathrm{Fe}$ anode at $0{ }^{\circ} \mathrm{C}$, yields up to $91 \%$ and stereoselectivities up to $96 \%$ ee were obtained (Scheme 16). Control experiments showed that the reaction does not occur in absence of $\mathrm{Ni}$ or current, while $\mathrm{Mn}^{0}$ or $\mathrm{Zn}^{0}$ as alternative reductants afforded lower yields and slightly lower $e e^{\prime}$ s. CV analysis indicated that the Ni catalyst is preferentially reduced 
over the substrate, and that the latter can undergo oxidative addition to $\mathrm{Ni}^{0}$. The authors suggested a reductive coupling mechanism analogous to that suggested for Reisman's work (Scheme 15), in which cathodic reduction of the initial complex to $\mathrm{Ni}^{0}$, followed by oxidative addition of the aryl bromide, results in a $\mathrm{Ni}^{\mathrm{II}}$ complex. Subsequent cathodic reduction to $\mathrm{Ni}^{\mathrm{I}}$ and oxidative addition of another molecule of the aryl bromide substrate generates a NiII intermediate. Reductive elimination releases the biaryl product, while the $\mathrm{Ni}^{\mathrm{I}}$ species undergoes further electrochemical reduction to close the catalytic cycle. However, the authors state that other pathways could not be ruled out at this stage.

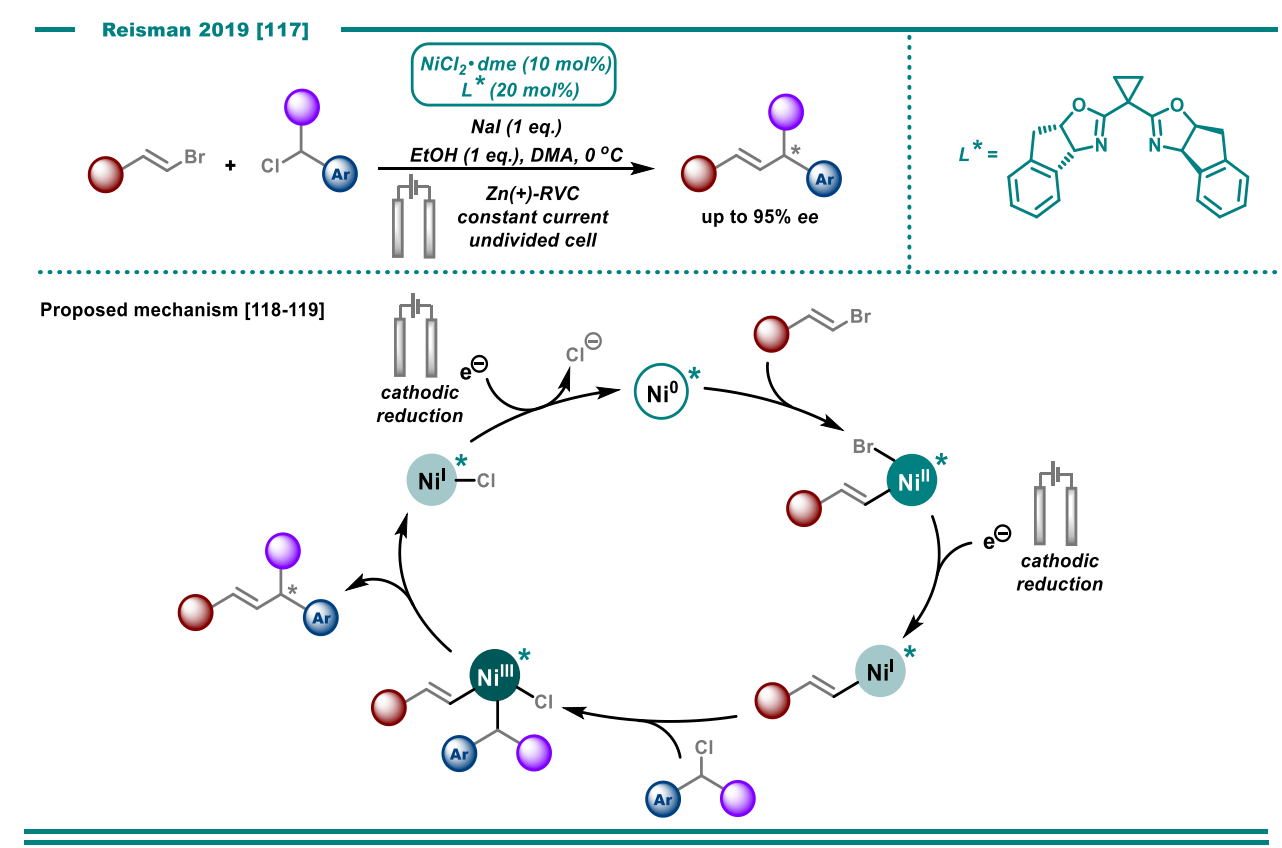

Scheme 15. Electrochemically driven cross-electrophile coupling with Ni-catalysis.

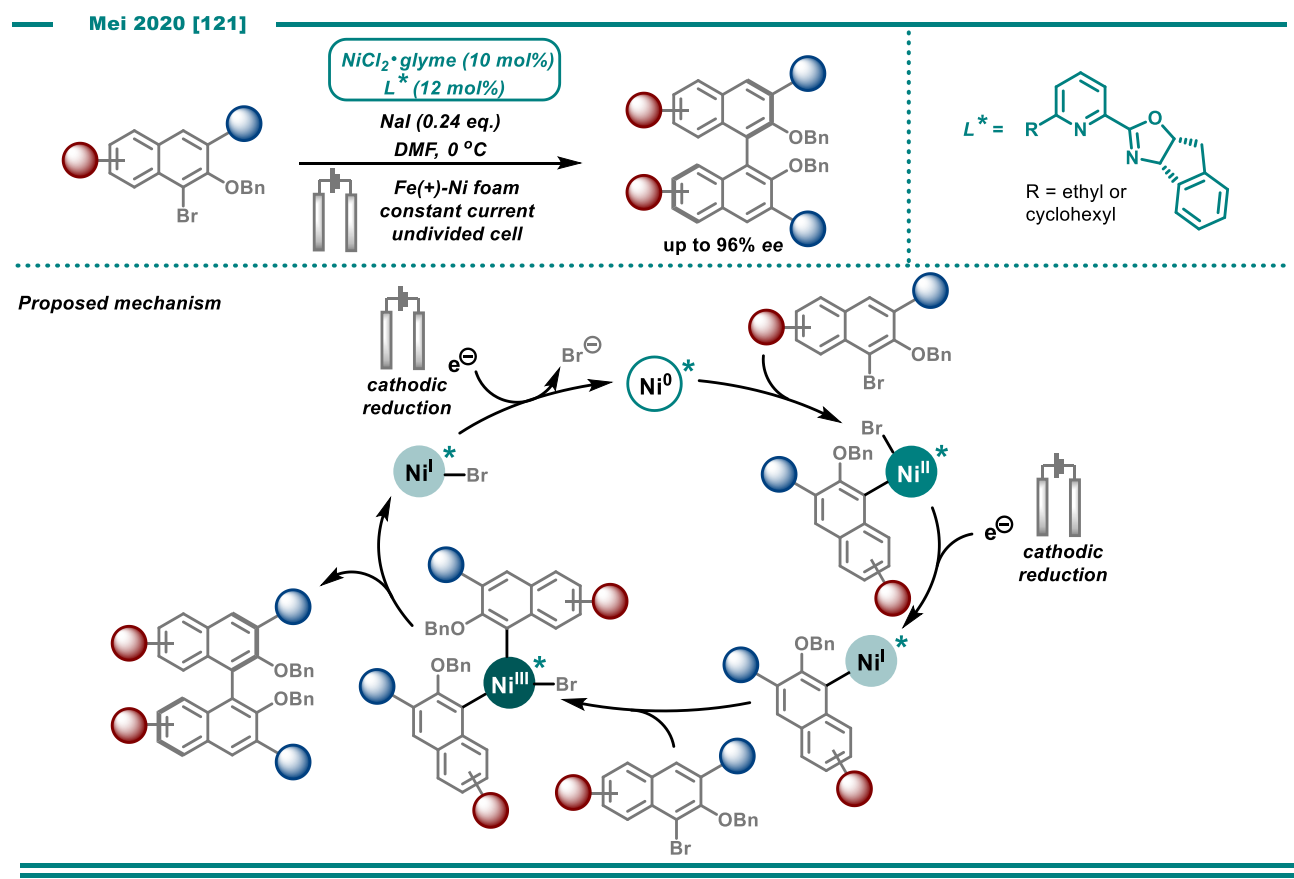

Scheme 16. Reductive cross-electrophile coupling for the formation of axially chiral biaryls using Ni-catalysis under electrochemical conditions. 


\section{Conclusions and Outlook}

Asymmetric catalysis under electrosynthetic conditions is a rapidly expanding research field that has equipped the organic chemist toolbox with new methods for enantioselective synthesis of organic molecules in the last few years, not the least for electrochemically driven metal catalysis. In comparison with the use of pre-functionalized chiral electrodes, chiral electrolytes or solvents or pre-modified substrates with chiral auxiliaries, homogeneous catalysis for the conversion of prochiral substrates appears as an economical, user-friendly and modular approach for asymmetric electrosynthesis [3-6]. It can be noted that the use of electricity to promote enantioselective oxidative processes is currently considerably more explored compared to its use in reductive transformations. As such, further developments on the latter topic can be anticipated.

Electrosynthesis offers the possibility to bypass the use of (super)stoichiometric and commonly hazardous and toxic chemical redox reagents, which results in increased safety and atom efficiency of the processes. On the other hand, large amounts of electrolyte are typically required to provide sufficient conductivity to the organic medium, which clearly hampers atom efficiency. Development of easily recyclable electrolytes, economic ionic liquids or microfluidic systems that make electrolytes superfluous due to the small distance between cathode and anode are interesting possibilities to address this problem that may promote the transition from academic research to industrial processes for the synthesis of fine chemicals [122,123]. Up until now, however, such approaches have not been applied for asymmetric catalysis. Furthermore, the energy efficiency of electrosynthetic processes is not necessarily optimized as more current is typically required to transform starting material into product compared to what theory would suggest. This Faradaic loss may be partly addressed by the use of redox mediators for indirect electrolysis. As redox mediators can allow for redox events to occur at lower potentials (in absolute numbers), this may also enable higher selectivities and functional group tolerance [15]. There is plenty of room for innovation in this field, not the least for reductive transformations, and inspiration for electrosynthetic applications is likely to be found in photoredox catalysis, as well as the proceedings of the organic battery community [124].

It can be noted that chiral amines and derivatives thereof play a key role for asymmetric catalysis in an electrosynthetic setting, either as organocatalysts or as ligands in metal-catalyzed systems. In this light, future development of other chiral inductors will be interesting. For example, chiral hypervalent iodine reagents were recently demonstrated to induce optical activity in organic molecules under electrosynthetic conditions [125]. As electrochemical synthesis of hypervalent halogen compounds has been demonstrated viable [126-129] and the use of halides and halogen compounds as electrochemical redox mediators is already known $[40,69,70,130]$, future developments in this area are anticipated.

Author Contributions: Conceptualization, C.M. and H.L.; writing-original draft preparation, C.M. and H.L.; writing-review and editing, C.M. and H.L.; supervision, H.L.; project administration, H.L.; funding acquisition, H.L. All authors have read and agreed to the published version of the manuscript.

Funding: This research was funded by The Swedish Research Council, grant number 2015-06466, and Stiftelsen Olle Engkvist Byggmästare. Magnus Bergvalls stiftelse C.F. Lundströms stiftelse (The Royal Swedish Academy of Agriculture and Forestry) Stiftelsen Lars Hiertas minne.

Acknowledgments: We gratefully acknowledge Piret Villo for valuable feedback on the manuscript.

Conflicts of Interest: The authors declare no conflict of interest.

\section{References}

1. Trost, B.M. Asymmetric catalysis: An enabling science. Proc. Nat. Acad. Sci. USA 2004, 101, 5348. [CrossRef]

2. Ojima, I. Catalytic Asymmetric Synthesis, 3rd ed.; John Wiley \& Sons, Inc.: Hoboken, NJ, USA, 2010.

3. Chang, X.; Zhang, Q.; Guo, C. Asymmetric Electrochemical Transformations. Angew. Chem. Int. Ed. 2020, 59, 12612-12622. [CrossRef] [PubMed]

4. Lin, Q.; Li, L.; Luo, S. Asymmetric Electrochemical Catalysis. Chem. Eur. J. 2019, 25, 10033-10044. [CrossRef] [PubMed] 
5. Ghosh, M.; Shinde, V.S.; Rueping, M. A review of asymmetric synthetic organic electrochemistry and electrocatalysis: Concepts, applications, recent developments and future directions. Beilstein J. Org. Chem. 2019, 15, 2710-2746. [CrossRef] [PubMed]

6. Ogawa, K.A.; Boydston, A.J. Recent Developments in Organocatalyzed Electroorganic Chemistry. Chem. Lett. 2015, 44, 10-16. [CrossRef]

7. Wang, K.; Kong, W. Recent Advances in Transition Metal-Catalyzed Asymmetric Radical Reactions. Chin. J. Chem. 2018, 36, 247-256. [CrossRef]

8. Saha, D. Catalytic Enantioselective Radical Transformations Enabled by Visible Light. Chem. Asian J. 2020, 15, 2129-2152. [CrossRef]

9. Sibi, M.P.; Manyem, S.; Zimmerman, J. Enantioselective Radical Processes. Chem. Rev. 2003, 103, 3263-3296. [CrossRef]

10. Jiang, C.; Chen, W.; Zheng, W.-H.; Lu, H. Advances in asymmetric visible-light photocatalysis. 2015-2019, Org. Biomol. Chem. 2019, 17, 8673-8689.

11. Siu, J.C.; Fu, N.; Lin, S. Catalyzing Electrosynthesis: A Homogeneous Electrocatalytic Approach to Reaction Discovery. Acc. Chem. Res. 2020, 53, 547-560. [CrossRef]

12. Francke, R. Integrating Catalytic Processes and Modern Electrolyte Concepts into Electrosynthesis. CHIMIA 2020, 74, 49-56. [CrossRef]

13. Kärkäs, M.D. Electrochemical strategies for $\mathrm{C}-\mathrm{H}$ functionalization and $\mathrm{C}-\mathrm{N}$ bond formation. Chem. Soc. Rev. 2018, 47, 5786-5865. [CrossRef] [PubMed]

14. Yan, M.; Kawamata, Y.; Baran, P.S. Synthetic Organic Electrochemical Methods Since 2000: On the Verge of a Renaissance. Chem. Rev. 2017, 117, 13230-13319. [CrossRef]

15. Francke, R.; Little, R.D. Redox catalysis in organic electrosynthesis: Basic principles and recent developments. Chem. Soc. Rev. 2014, 43, 2492-2521. [CrossRef] [PubMed]

16. Pollok, D.; Waldvogel, S.R. Electro-organic synthesis-A 21st century technique. Chem. Sci. 2020. [CrossRef]

17. Krištofíková, D.; Modrocká, V.; Mečiarová, M.; Šebesta, R. Green Asymmetric Organocatalysis. ChemSusChem 2020, 13, 2828-2858. [CrossRef] [PubMed]

18. Atobe, M. Organic electrosynthesis in flow microreactor. Curr. Opin. Electrochem. 2017, 2, 1-6. [CrossRef]

19. Schäfer, H.J. Contributions of organic electrosynthesis to green chemistry. Comptes Rendus Chim. 2011, 14, 745-765. [CrossRef]

20. Moeller, K.D. Using Physical Organic Chemistry To Shape the Course of Electrochemical Reactions. Chem. Rev. 2018, 118, 4817-4833. [CrossRef]

21. Heard, D.; Lennox, A. Electrode Materials in Modern Organic Electrochemistry. Angew. Chem. Int. Ed. 2020, accepted. [CrossRef]

22. Sandford, C.; Edwards, M.A.; Klunder, K.J.; Hickey, D.P.; Li, M.; Barman, K.; Sigman, M.S.; White, H.S.; Minteer, S.D. A synthetic chemist's guide to electroanalytical tools for studying reaction mechanisms. Chem. Sci. 2019, 10, 6404-6422. [CrossRef] [PubMed]

23. $\mathrm{Wu}, \mathrm{R} . ; \mathrm{Ma}, \mathrm{C}$; Zhu, Z. Enzymatic electrosynthesis as an emerging electrochemical synthesis platform. Curr. Opin. Electrochem. 2020, 19, 1-7. [CrossRef]

24. Cadoux, C.; Milton, R.D. Recent Enzymatic Electrochemistry for Reductive Reactions. ChemElectroChem 2020, 7, 1974-1986. [CrossRef]

25. Kohlmann, C.; Märkle, W.; Lütz, S. Electroenzymatic synthesis. J. Mol. Catal. B Enzym. 2008, 51, 57-72. [CrossRef]

26. Zhu, L.; Wang, D.; Jia, Z.; Lin, Q.; Huang, M.; Luo, S. Catalytic Asymmetric Oxidative Enamine Transformations. ACS Catal. 2018, 8, 5466-5484. [CrossRef]

27. Bui, N.-N.; Ho, X.-H.; Mho, S.-i.; Jang, H.-Y. Organocatalyzed $\alpha$-Oxyamination of Aldehydes Using Anodic Oxidation. Eur. J. Org. Chem. 2009, 2009, 5309-5312. [CrossRef]

28. Ho, X.-H.; Mho, S.-i.; Kang, H.; Jang, H.-Y. Electro-Organocatalysis: Enantioselective $\alpha$-Alkylation of Aldehydes. Eur. J. Org. Chem. 2010, 2010, 4436-4441. [CrossRef]

29. Jensen, K.L.; Franke, P.T.; Nielsen, L.T.; Daasbjerg, K.; Jørgensen, K.A. Anodic Oxidation and Organocatalysis: Direct Regio- and Stereoselective Access to meta-Substituted Anilines by $\alpha$-Arylation of Aldehydes. Angew. Chem. Int. Ed. 2010, 49, 129-133. [CrossRef]

30. Fu, N.; Li, L.; Yang, Q.; Luo, S. Catalytic Asymmetric Electrochemical Oxidative Coupling of Tertiary Amines with Simple Ketones. Org. Lett. 2017, 19, 2122-2125. [CrossRef] 
31. Osa, T.; Kashiwagi, Y.; Yanagisawa, Y.; Bobbitt, J.M. Enantioselective, electrocatalytic oxidative coupling of naphthol, naphthyl ether and phenanthrol on a TEMPO-modified graphite felt electrode in the presence of (-)-sparteine (TEMPO = 2,2,6,6-tetramethylpiperidin-1-yloxyl). J. Chem. Soc. Chem. Commun. 1994, 21, 2535-2537. [CrossRef]

32. Kashiwagi, Y.; Yanagisawa, Y.; Kurashima, F.; Anzai, J.-i.; Osa, T.; Bobbitt, J.M. Enantioselective electrocatalytic oxidation of racemic alcohols on a TEMPO-modified graphite felt electrode by use of chiral base (TEMPO = 2,2,6,6-tetramethylpiperidin-1-yloxyl). Chem. Commun. 1996, 24, 2745-2746. [CrossRef]

33. Yoshinori, Y.; Yoshitomo, K.; Futoshi, K.; Jun-ichi, A.; Tetsuo, O.; Enantioselective, B.J.M. Electrocatalytic Lactonization of Methyl-substituted Diols on a TEMPO-modified Graphite Felt Electrode in the Presence of (-)-Sparteine. Chem. Lett. 1996, 25, 1043-1044.

34. Kashiwagi, Y.; Kurashima, F.; Kikuchi, C.; Anzai, J.-i.; Osa, T.; Bobbitt, J.M. Enantioselective electrocatalytic oxidation of racemic sec-alcohols using a chiral 1-azaspiro [5.5]undecane-N-oxyl radical. Tetrahedron Lett. 1999, 40, 6469-6472. [CrossRef]

35. Kashiwagi, Y.; Kurashima, F.; Kikuchi, C.; Anzai, J.-i.; Osa, T.; Bobbitt, J.M. Enantioselective electrocatalytic oxidation of racemic amines using a chiral 1-azaspiro[5.5] undecane N-oxyl radical. Chem. Commun. 1999, 1983-1984. [CrossRef]

36. Kuroboshi, M.; Yoshihisa, H.; Cortona, M.N.; Kawakami, Y.; Gao, Z.; Tanaka, H. Electro-oxidative kinetic resolution of sec-alcohols by using an optically active N-oxyl mediator. Tetrahedron Lett. 2000, 41, 8131-8135. [CrossRef]

37. Tanaka, H.; Kawakami, Y.; Goto, K.; Kuroboshi, M. An aqueous silica gel disperse electrolysis system. N-Oxyl-mediated electrooxidation of alcohols. Tetrahedron Lett. 2001, 42, 445-448. [CrossRef]

38. Shiigi, H.; Mori, H.; Tanaka, T.; Demizu, Y.; Onomura, O. Chiral azabicyclo-N-oxyls mediated enantioselective electrooxidation of sec-alcohols. Tetrahedron Lett. 2008, 49, 5247-5251. [CrossRef]

39. Wang, F.; Stahl, S.S. Electrochemical Oxidation of Organic Molecules at Lower Overpotential: Accessing Broader Functional Group Compatibility with Electron-Proton Transfer Mediators. Acc. Chem. Res. 2020, 53, 561-574. [CrossRef]

40. Minato, D.; Arimoto, H.; Nagasue, Y.; Demizu, Y.; Onomura, O. Asymmetric electrochemical oxidation of 1,2-diols, aminoalcohols, and aminoaldehydes in the presence of chiral copper catalyst. Tetrahedron 2008, 64, 6675-6683. [CrossRef]

41. Gao, P.-S.; Weng, X.-J.; Wang, Z.-H.; Zheng, C.; Sun, B.; Chen, Z.-H.; You, S.-L.; Mei, T.-S. $\mathrm{Cu}^{\mathrm{II}} / \mathrm{TEMPO}-$ Catalyzed Enantioselective $\mathrm{C}\left(\mathrm{sp}^{3}\right)-\mathrm{H}$ Alkynylation of Tertiary Cyclic Amines through Shono-Type Oxidation. Angew. Chem. Int. Ed. 2020, 59, 15254-15259. [CrossRef]

42. Shono, T.; Hamaguchi, H.; Matsumura, Y. Electroorganic chemistry. XX. Anodic oxidation of carbamates. J. Am. Chem. Soc. 1975, 97, 4264-4268. [CrossRef]

43. Lu, F.-Y.; Chen, Y.-J.; Chen, Y.; Ding, X.; Guan, Z.; He, Y.-H. Highly enantioselective electrosynthesis of C2-quaternary indolin-3-ones. Chem. Commun. 2020, 56, 623-626. [CrossRef] [PubMed]

44. Mukherjee, S.; Yang, J.W.; Hoffmann, S.; List, B. Asymmetric Enamine Catalysis. Chem. Rev. 2007, 107, 5471-5569. [CrossRef] [PubMed]

45. Li, L.; Li, Y.; Fu, N.; Zhang, L.; Luo, S. Catalytic Asymmetric Electrochemical $\alpha$-Arylation of Cyclic $\beta$-Ketocarbonyls with Anodic Benzyne Intermediates. Angew. Chem. Int. Ed. 2020, 59, 14347-14351. [CrossRef] [PubMed]

46. Campbell, C.D.; Rees, C.W. Reactive intermediates. Part I. Synthesis and oxidation of 1- and 2-aminobenzotriazole. J. Chem. Soc. C 1969, 742-747. [CrossRef]

47. Kato, H.; Nakazawa, S.; Kiyosawa, T.; Hirakawa, K. Heterocycles by cycloaddition. Part II. Cycloaddition-extrusion reactions of five-membered mesoionic compounds with benzyne: Prepartion of benz[c]azole and benzo[c]thiophen derivatives. J. Chem. Soc. Perkin Trans. 1 1976, 672-675. [CrossRef]

48. Rigby, J.H.; Holsworth, D.D.; James, K. Vinyl isocyanates in synthesis. [4 + 2] Cycloaddition reactions with benzyne addends. J. Org. Chem. 1989, 54, 4019-4020. [CrossRef]

49. Sakurai, H.; Sakaba, H.; Nakadaira, Y. Facile preparation of 2,3-benzo-1,4-diphenyl-7-silanorbornadiene derivatives and the first clear evidence of silylene-to-disilene thermal rearrangement. J. Am. Chem. Soc. 1982, 104, 6156-6158. [CrossRef]

50. Cresp, T.M.; Wege, D. The addition of benzyne to azulene. Tetrahedron 1986, 42, 6713-6718. [CrossRef] 
51. Huang, X.; Zhang, Q.; Lin, J.; Harms, K.; Meggers, E. Electricity-driven asymmetric Lewis acid catalysis. Nat. Catal. 2019, 2, 34-40. [CrossRef]

52. Zhang, Q.; Chang, X.; Peng, L.; Guo, C. Asymmetric Lewis Acid Catalyzed Electrochemical Alkylation. Angew. Chem. Int. Ed. 2019, 58, 6999-7003. [CrossRef] [PubMed]

53. Jeffrey, J.L.; Terrett, J.A.; MacMillan, D.W.C. O-H hydrogen bonding promotes H-atom transfer from $\alpha$ C-H bonds for C-alkylation of alcohols. Science 2015, 349, 1532-1536. [CrossRef] [PubMed]

54. Shaw, M.H.; Shurtleff, V.W.; Terrett, J.A.; Cuthbertson, J.D.; MacMillan, D.W.C. Native functionality in triple catalytic cross-coupling: $\mathrm{sp}^{3} \mathrm{C}-\mathrm{H}$ bonds as latent nucleophiles. Science 2016, 352, 1304. [CrossRef] [PubMed]

55. Le, C.; Liang, Y.; Evans, R.W.; Li, X.; MacMillan, D.W.C. Selective sp ${ }^{3}$ C-H alkylation via polarity-match-based cross-coupling. Nature 2017, 547, 79-83. [CrossRef]

56. Zhang, X.; MacMillan, D.W.C. Direct aldehyde C-H arylation and alkylation via the combination of nickel, hydrogen atom transfer, and photoredox catalysis. J. Am. Chem. Soc. 2017, 139, 11353-11356. [CrossRef]

57. Twilton, J.; Christensen, M.; DiRocco, D.A.; Ruck, R.T.; Davies, I.W.; MacMillan, D.W.C. Selective Hydrogen Atom Abstraction through Induced Bond Polarization: Direct a-Arylation of Alcohols through Photoredox, HAT, and Nickel Catalysis. Angew. Chem. Int. Ed. 2018, 57, 5369-5373. [CrossRef] [PubMed]

58. Yang, H.-B.; Feceu, A.; Martin, D.B.C. Catalyst-Controlled C-H Functionalization of Adamantanes Using Selective H-Atom Transfer. ACS Catal. 2019, 9, 5708-5715. [CrossRef]

59. Chang, X.; Zhang, J.; Zhang, Q.; Guo, C. Merging Electrosynthesis and Bifunctional Squaramide Catalysis in the Asymmetric Detrifluoroacetylative Alkylation Reactions. Angew. Chem. Int. Ed. 2020, accepted. [CrossRef]

60. Dhawa, U.; Tian, C.; Wdowik, T.; Oliveira, J.C.A.; Hao, J.; Ackermann, L. Enantioselective Palladaelectro-Catalyzed C-H Activations by Transient Directing Groups: Expedient Access to Helicenes. Angew. Chem. Int. Ed. 2020, 59, 13451-13457. [CrossRef]

61. Hentges, S.G.; Sharpless, K.B. Asymmetric induction in the reaction of osmium tetroxide with olefins. J. Am. Chem. Soc. 1980, 102, 4263-4265. [CrossRef]

62. Sharpless, K.B.; Amberg, W.; Bennani, Y.L.; Crispino, G.A.; Hartung, J.; Jeong, K.S.; Kwong, H.L.; Morikawa, K.; Wang, Z.M. The osmium-catalyzed asymmetric dihydroxylation: A new ligand class and a process improvement. J. Org. Chem. 1992, 57, 2768-2771. [CrossRef]

63. Xu, D.; Crispino, G.A.; Sharpless, K.B. Selective asymmetric dihydroxylation (AD) of dienes. J. Am. Chem. Soc. 1992, 114, 7570-7571. [CrossRef]

64. Hoi-Lun, K.; Sorato, C.; Ogino, Y.; Hou, C.; Sharpless, K.B. Preclusion of the "second cycle" in the osmium-catalyzed asymmetric dihydroxylation of olefins leads to a superior process. Tetrahedron Lett. 1990, 31, 2999-3002. [CrossRef]

65. Minato, M.; Yamamoto, K.; Tsuji, J. Osmium tetraoxide catalyzed vicinal hydroxylation of higher olefins by using hexacyanoferrate(III) ion as a cooxidant. J. Org. Chem. 1990, 55, 766-768. [CrossRef]

66. Ogino, Y.; Chen, H.; Kwong, H.-L.; Sharpless, K.B. On the timing of hydrolysis/reoxidation in the osmium-catalyzed asymmetric dihydroxylation of olefins using potassium ferricyanide as the reoxidant. Tetrahedron Lett. 1991, 32, 3965-3968. [CrossRef]

67. Amundsen, A.R.; Balko, E.N. Preparation of chiral diols by the osmium-catalysed, indirect anodic oxidation of olefins. J. Appl. Electrochem. 1992, 22, 810-816. [CrossRef]

68. Torii, S.; Liu, P.; Tanaka, H. Electrochemical Os-Catalyzed Asymmetric Dihydroxylation of Olefins with Sharpless' Ligand. Chem. Lett. 1995, 24, 319-320. [CrossRef]

69. Torii, S.; Liu, P.; Bhuvaneswari, N.; Amatore, C.; Jutand, A. Chemical and Electrochemical Asymmetric Dihydroxylation of Olefins in $\mathrm{I}_{2}-\mathrm{K}_{2} \mathrm{CO}_{3}-\mathrm{K}_{2} \mathrm{OsO}_{2}(\mathrm{OH})_{4}$ and $\mathrm{I}_{2}-\mathrm{K}_{3} \mathrm{PO}_{4} / \mathrm{K}_{2} \mathrm{HPO}_{4}-\mathrm{K}_{2} \mathrm{OsO}_{2}(\mathrm{OH})_{4}$ Systems with Sharpless' Ligand. J. Org. Chem. 1996, 61, 3055-3060. [CrossRef]

70. Tanaka, H.; Kuroboshi, M.; Takeda, H.; Kanda, H.; Torii, S. Electrochemical asymmetric epoxidation of olefins by using an optically active Mn-salen complex. J. Electroanal. Chem. 2001, 507, 75-81. [CrossRef]

71. Irie, R.; Noda, K.; Ito, Y.; Matsumoto, N.; Katsuki, T. Catalytic asymmetric epoxidation of unfunctionalized olefins. Tetrahedron Lett. 1990, 31, 7345-7348. [CrossRef]

72. Zhang, W.; Loebach, J.L.; Wilson, S.R.; Jacobsen, E.N. Enantioselective epoxidation of unfunctionalized olefins catalyzed by salen manganese complexes. J. Am. Chem. Soc. 1990, 112, 2801-2803. [CrossRef]

73. Katsuki, T. Mn-salen catalyst, competitor of enzymes, for asymmetric epoxidation. J. Mol. Catal. A 1996, 113, 87-107. [CrossRef] 
74. Page, P.C.B.; Marken, F.; Williamson, C.; Chan, Y.; Buckley, B.R.; Bethell, D. Enantioselective Organocatalytic Epoxidation Driven by Electrochemically Generated Percarbonate and Persulfate. Adv. Synth. Catal. 2008, 350, 1149-1154. [CrossRef]

75. Nguyen, B.H.; Perkins, R.J.; Smith, J.A.; Moeller, K.D. Photovoltaic-driven organic electrosynthesis and efforts toward more sustainable oxidation reactions. Beilstein J. Org. Chem. 2015, 11, 280-287. [CrossRef]

76. Nguyen, B.H.; Redden, A.; Moeller, K.D. Sunlight, electrochemistry, and sustainable oxidation reactions. Green Chem. 2014, 16, 69-72. [CrossRef]

77. Fu, N.; Song, L.; Liu, J.; Shen, Y.; Siu, J.C.; Lin, S. New Bisoxazoline Ligands Enable Enantioselective Electrocatalytic Cyanofunctionalization of Vinylarenes. J. Am. Chem. Soc. 2019, 141, 14480-14485. [CrossRef]

78. Song, L.; Fu, N.; Ernst, B.G.; Lee, W.H.; Frederick, M.O.; DiStasio, R.A.; Lin, S. Dual Electrocatalysis Enables Enantioselective Hydrocyanation of Conjugated Alkenes. Nat. Chem. 2020, 12, 747-754. [CrossRef]

79. Gourley, R.N.; Grimshaw, J.; Millar, P.G. Electrochemical reduction in the presence of tertiary amines: An asymmetric synthesis of 3, 4-dihydro-4-methylcoumarin. Chem. Commun. 1967, 1278-1279. [CrossRef]

80. Gourley, R.N.; Grimshaw, J.; Millar, P.G. Electrochemical reactions. Part VIII. Asymmetric induction during the reduction of coumarins modified by the presence of tertiary amines. J. Chem. Soc. C 1970, 2318-2323. [CrossRef]

81. Höweler, U.; Schoo, N.; Schäfer, H.-J. Enantioselective cathodic reduction of 4-substituted coumarins with alkaloids as catalysts, 2. AM1 and force-field study of the transition-state model. Liebigs Ann. Chem. 1993, 1993, 609-614. [CrossRef]

82. Schoo, N.; Schäfer, H.-J. Electroorganic Synthesis, 54. Enantioselective Cathodic Reduction of 4-Substituted Coumarins with Alkaloids as Catalysts, 1. Liebigs Ann. Chem. 1993, 1993, 601-607. [CrossRef]

83. Nielsen, M.F.; Batanero, B.; Löhl, T.; Schäfer, H.J.; Würthwein, E.-U.; Fröhlich, R. Enantioselective Cathodic Reduction of 4-Methylcoumarin: Dependence of Selectivity on Reaction Conditions and Investigation of the Mechanism. Chem. Eur. J. 1997, 3, 2011-2024. [CrossRef]

84. Kariv, E.; Terni, H.A.; Gileadi, E. The role of quinidine in induction of asymmetric synthesis at mercury cathodes. Electrochim. Acta 1973, 18, 433-441. [CrossRef]

85. Chen, B.-L.; Xiao, Y.; Xu, X.-M.; Yang, H.-P.; Wang, H.; Lu, J.-X. Alkaloid induced enantioselective electroreduction of acetophenone. Electrochim. Acta 2013, 107, 320-326. [CrossRef]

86. Kariv, E.; Terni, H.A.; Gileadi, E. Asymmetric Induction by Alkaloids in Electrolytic Reductions. J. Electrochem. Soc. 1973, 120, 639. [CrossRef]

87. Hermolin, J.; Kopilov, J.; Gileadi, E. Asymmetric reduction of 2- and 4-acetylpyridine in the presence of strychnine. J. Electroanal. Chem. 1976, 71, 245-248. [CrossRef]

88. Kopilov, J.; Shatzmiller, S.; Kariv, E. Asymmetric induction in reduction of acetyl pyridines at a mercury cathode. Electrochim. Acta 1976, 21, 535-536. [CrossRef]

89. Kopilov, J.; Kariv, E.; Miller, L.L. Asymmetric, cathodic reduction of acetylpyridines. J. Am. Chem. Soc. 1977, 99, 3450-3454. [CrossRef]

90. Yadav, A.K.; Singh, A. Enantioselective Cathodic Reduction of Some Prochiral Ketones in the Presence of (1R,2S)-(-)-N,N-Dimethylephedrinium Tetrafluoroborate at a Mercury Pool Cathode. Bull. Chem. Soc. Jpn. 2002, 75, 587-588. [CrossRef]

91. Yadav, A.K.; Manju, M.P.; Chhinpa, R. Enantioselective cathodic reduction of some prochiral ketones in the presence of (-)-N, $\mathrm{N}^{\prime}$-dimethylquininium tetrafluoroborate at mercury cathode. Tetrahedron Asymmetry 2003, 14, 1079-1081. [CrossRef]

92. Vago, M.; Williams, F.J.; Calvo, E.J. Enantioselective electrocatalytic hydrogenation of ethyl pyruvate on carbon supported Pd electrodes. Electrochem. Commun. 2007, 9, 2725-2728. [CrossRef]

93. Jubault, M.; Raoult, E.; Armand, J.; Boulares, L. Effect of cathodic potential on the electrochemical synthesis of optically active amino-acids. J. Chem. Soc. Chem. Commun. 1977, 250-251. [CrossRef]

94. Jubault, M.; Raoult, E.; Peltier, D. Preprotonation of the substrate by protonated alkaloid in asymmetric electrosynthesis. J. Chem. Soc. Chem. Commun. 1979, 232-233. [CrossRef]

95. Jubault, M. Effect of alkaloid concentration in asymmetric electrosynthesis. J. Chem. Soc. Chem. Commun. 1980, 953-954. [CrossRef]

96. Park, J.W.; Choi, M.H.; Park, K.K. Electrocatalytic reduction of benzoylformic acid mediated by methyl viologen. Tetrahedron Lett. 1995, 36, 2637-2638. [CrossRef] 
97. Hazard, R.; Jaouannet, S.; Tallec, A. Stereochemistry of electroreductions of bromocyclopropanes: 1-asymmetric electrochemical synthesis by reduction at a mercury cathode in the presence of adsorbed alkaloids. Tetrahedron 1982, 38, 93-102. [CrossRef]

98. Moutet, J.-C.; Cho, L.Y.; Duboc-Toia, C.; Ménage, S.; Riesgo, E.C.; Thummel, R.P. Heterogeneous and homogeneous asymmetric electrocatalytic hydrogenation with rhodium(III) complexes containing chiral polypyridyl ligands. New J. Chem. 1999, 23, 939-944. [CrossRef]

99. Ohno, T.; Nishioka, T.; Hisaeda, Y.; Murakami, Y. Hydrophobic vitamin B12: Part 13. Asymmetric reaction of hydrophobic vitamin B12 under electrochemical conditions and rationalization of enantioselectivity based on conformational analysis. J. Mol. Struct. 1994, 308, 207-218. [CrossRef]

100. Hisaeda, Y.; Nishioka, T.; Inoue, Y.; Asada, K.; Hayashi, T. Electrochemical reactions mediated by vitamin B12 derivatives in organic solvents. Coord. Chem. Rev. 2000, 198, 21-37. [CrossRef]

101. Su, H.; Walder, L.; Zhang, Z.-d.; Scheffold, R. Asymmetric Catalysis by Vitamin $B_{12}$. The isomerization of achiral epoxides to optically active allylic alcohols. Helv. Chim. Acta 1988, 71, 1073-1078. [CrossRef]

102. Franco, D.; Riahi, A.; Hénin, F.; Muzart, J.; Duñach, E. Electrochemical Reduction of a Racemic Allyl $\beta$-Keto Ester Catalyzed by Nickel Complexes: Asymmetric Induction. Eur. J. Org. Chem. 2002, 2002, 2257-2259. [CrossRef]

103. Hori, Y. Modern Aspects of Electrochemistry; Vayenas, C.G., White, R.E., Gamboa-Aldeco, M.E., Eds.; Springer: New York, NY, USA, 2008; pp. 89-189.

104. Liu, Y.; Li, F.; Zhang, X.; Ji, X. Recent progress on electrochemical reduction of $\mathrm{CO}_{2}$ to methanol. Curr. Opin. Green Sustain. Chem. 2020, 23, 10-17. [CrossRef]

105. Nitopi, S.; Bertheussen, E.; Scott, S.B.; Liu, X.; Engstfeld, A.K.; Horch, S.; Seger, B.; Stephens, I.E.L.; Chan, K.; Hahn, C.; et al. Progress and Perspectives of Electrochemical CO2 Reduction on Copper in Aqueous Electrolyte. Chem. Rev. 2019, 119, 7610-7672. [CrossRef] [PubMed]

106. Lv, J.-J.; Jouny, M.; Luc, W.; Zhu, W.; Zhu, J.-J.; Jiao, F. A Highly Porous Copper Electrocatalyst for Carbon Dioxide Reduction. Adv. Mater. 2018, 30, 1803111. [CrossRef] [PubMed]

107. Zhu, W.; Kattel, S.; Jiao, F.; Chen, J.G. Shape-Controlled $\mathrm{CO}_{2}$ Electrochemical Reduction on Nanosized Pd Hydride Cubes and Octahedra. Adv. Energy Mater. 2019, 9, 1802840. [CrossRef]

108. Zhang, K.; Wang, H.; Zhao, S.-F.; Niu, D.-F.; Lu, J.-X. Asymmetric electrochemical carboxylation of prochiral acetophenone: An efficient route to optically active atrolactic acid via selective fixation of carbon dioxid. J. Electroanal. Chem. 2009, 630, 35-41. [CrossRef]

109. Zhao, S.-F.; Zhu, M.-X.; Zhang, K.; Wang, H.; Lu, J.-X. Alkaloid induced asymmetric electrocarboxylation of 4-methylpropiophenone. Tetrahedron Lett. 2011, 52, 2702-2705. [CrossRef]

110. Chen, B.-L.; Tu, Z.-Y.; Zhu, H.-W.; Sun, W.-W.; Wang, H.; Lu, J.-X. $\mathrm{CO}_{2}$ as a C1-organic building block: Enantioselective electrocarboxylation of aromatic ketones with $\mathrm{CO}_{2}$ catalyzed by cinchona alkaloids under mild conditions. Electrochim. Acta 2014, 116, 475-483. [CrossRef]

111. Chen, B.-L.; Zhu, H.-W.; Xiao, Y.; Sun, Q.-L.; Wang, H.; Lu, J.-X. Asymmetric electrocarboxylation of 1-phenylethyl chloride catalyzed by electrogenerated chiral [CoI(salen)]-complex. Electrochem. Commun. 2014, 42, 55-59. [CrossRef]

112. Jiao, K.-J.; Li, Z.-M.; Xu, X.-T.; Zhang, L.-P.; Li, Y.-Q.; Zhang, K.; Mei, T.-S. Palladium-catalyzed reductive electrocarboxylation of allyl esters with carbon dioxide. Org. Chem. Front. 2018, 5, 2244-2248. [CrossRef]

113. Shatskiy, A.; Lundberg, H.; Kärkäs, M.D. Organic Electrosynthesis: Applications in Complex Molecule Synthesis. ChemElectroChem 2019, 6, 4067-4092. [CrossRef]

114. Everson, D.A.; Weix, D.J. Cross-Electrophile Coupling: Principles of Reactivity and Selectivity. J. Org. Chem. 2014, 79, 4793-4798. [CrossRef] [PubMed]

115. Goldfogel, M.J.; Huang, L.; Weix, D.J. Cross-Electrophile Coupling: Principles and New Reactions. In Nickel Catalysis in Synthesis: Methods and Reactions; Ogoshi, S., Ed.; Wiley-VCH: Weinheim, Germany, 2020; Volume 352.

116. Truesdell, B.L.; Hamby, T.B.; Sevov, C.S. General C(sp2)-C(sp3) Cross-Electrophile Coupling Reactions Enabled by Overcharge Protection of Homogeneous Electrocatalysts. J. Am. Chem. Soc. 2020, 142, 5884-5893. [CrossRef] [PubMed]

117. DeLano, T.J.; Reisman, S.E. Enantioselective Electroreductive Coupling of Alkenyl and Benzyl Halides via Nickel Catalysis. ACS Catal. 2019, 9, 6751-6754. [CrossRef] 
118. Zhang, S.-K.; Samanta, R.C.; del Vecchio, A.; Ackermann, L. Evolution of High-Valent Nickela-Electrocatalyzed C-H Activation: From Cross(-Electrophile)-Couplings to Electrooxidative C-H Transformations. Chem. Eur. J. 2020, 26, 10936-10947. [CrossRef]

119. Poremba, K.E.; Dibrell, S.E.; Reisman, S.E. Nickel-Catalyzed Enantioselective Reductive Cross-Coupling Reactions. ACS Catal. 2020, 10, 8237-8246. [CrossRef]

120. Cherney, A.H.; Reisman, S.E. Nickel-Catalyzed Asymmetric Reductive Cross-Coupling Between Vinyl and Benzyl Electrophiles. J. Am. Chem. Soc. 2014, 136, 14365-14368. [CrossRef]

121. Qiu, H.; Shuai, B.; Wang, Y.-Z.; Liu, D.; Chen, Y.-G.; Gao, P.-S.; Ma, H.-X.; Chen, S.; Mei, T.-S. Enantioselective Ni-Catalyzed Electrochemical Synthesis of Biaryl Atropisomers. J. Am. Chem. Soc. 2020, 142, 9872-9878. [CrossRef]

122. Mo, Y.; Lu, Z.; Rughoobur, G.; Patil, P.; Gershenfeld, N.; Akinwande, A.I.; Buchwald, S.L.; Jensen, K.F. Microfluidic electrochemistry for single-electron transfer redox-neutral reactions. Science 2020, 368, 1352-1357. [CrossRef]

123. Leech, M.C.; Garcia, A.D.; Petti, A.; Dobbs, A.P.; Lam, K. Organic electrosynthesis: From academia to industry. React. Chem. Eng. 2020, 5, 977-990. [CrossRef]

124. Anson, C.W.; Stahl, S.S. Mediated Fuel Cells: Soluble Redox Mediators and Their Applications to Electrochemical Reduction of $\mathrm{O} 2$ and Oxidation of H2, Alcohols, Biomass, and Complex Fuels. Chem. Rev. 2020, 120, 3749-3786. [CrossRef] [PubMed]

125. Gao, W.-C.; Xiong, Z.-Y.; Pirhaghani, S.; Wirth, T. Enantioselective Electrochemical Lactonization Using Chiral Iodoarenes as Mediators. Synthesis 2019, 51, 276-284. [CrossRef]

126. Broese, T.; Francke, R. Electrosynthesis Using a Recyclable Mediator-Electrolyte System Based on Ionically Tagged Phenyl Iodide and 1,1,1,3,3,3-Hexafluoroisopropanol. Org. Lett. 2016, 18, 5896-5899. [CrossRef] [PubMed]

127. Doobary, S.; Sedikides, A.T.; Caldora, H.P.; Poole, D.L.; Lennox, A.J.J. Electrochemical Vicinal Difluorination of Alkenes: Scalable and Amenable to Electron-Rich Substrates. Angew. Chem. Int. Ed. 2020, 59, 1155-1160. [CrossRef] [PubMed]

128. Francke, R. Electrogenerated hypervalent iodine compounds as mediators in organic synthesis. Curr. Opin. Electrochem. 2019, 15, 83-88. [CrossRef]

129. Massignan, L.; Tan, X.; Meyer, T.H.; Kuniyil, R.; Messinis, A.M.; Ackermann, L. C-H Oxygenation Reactions Enabled by Dual Catalysis with Electrogenerated Hypervalent Iodine Species and Ruthenium Complexes. Angew. Chem. Int. Ed. 2020, 59, 3184-3189. [CrossRef]

130. Liu, K.; Song, C.; Lei, A. Recent advances in iodine mediated electrochemical oxidative cross-coupling. Org. Biomol. Chem. 2018, 16, 2375-2387. [CrossRef] 